\title{
Evaluation of Saltstone Mixer Paddle Configuration for Improved Wear Resistance
}

M.M. Reigel

M.D. Fowley

B.R. Pickenheim

September 12, 2012

Savannah River National Laboratory Savannah River Nuclear Solutions, LLC Aiken, SC 29808

Prepared for the U.S. Department of Energy under contract number DE-AC09-08SR22470. 
SRNL-STI-2012-00549

Revision 0

\section{DISCLAIMER}

This work was prepared under an agreement with and funded by the U.S. Government. Neither the U.S. Government or its employees, nor any of its contractors, subcontractors or their employees, makes any express or implied:

1. warranty or assumes any legal liability for the accuracy, completeness, or for the use or results of such use of any information, product, or process disclosed; or

2. representation that such use or results of such use would not infringe privately owned rights; or

3. endorsement or recommendation of any specifically identified commercial product, process, or service.

Any views and opinions of authors expressed in this work do not necessarily state or reflect those of the United States Government, or its contractors, or subcontractors.

\section{Printed in the United States of America \\ Prepared for U.S. Department of Energy}


Keywords: Saltstone

Mixer

Wear Resistance

Retention: Permanent

\title{
Evaluation of Saltstone Mixer Paddle Configuration for Improved Wear Resistance
}

\author{
M.M. Reigel \\ M.D. Fowley \\ B.R. Pickenheim
}

September 12, 2012

Savannah River National Laboratory Savannah River Nuclear Solutions, LLC Aiken, SC 29808

Prepared for the U.S. Department of Energy under contract number DE-AC09-08SR22470. 


\section{REVIEWS AND APPROVALS}

AUTHORS:

M.M. Reigel, Engineering Process Development

Date

M.D. Fowley, Engineering Development Lab

Date

B.R. Pickenheim, Engineering Process Development

Date

TECHNICAL REVIEW:

E.K. Hansen, Engineering Process Development

Date

APPROVAL:

K.M. Fox, Manager

Date

Engineering Process Development

Date

S.L. Marra, Manager

Environmental \& Chemical Process Technology Research Programs

J.E. Occhipinti, Manager

Date

Waste Solidification Engineering 
SRNL-STI-2012-00549

Revision 0

\section{EXECUTIVE SUMMARY}

At the Savannah River Site (SRS), the Saltstone Production Facility (SPF) receives low level waste (LLW) salt solution from Tank $50 \mathrm{H}$ for treatment and disposal. At the SPF, the LLW is mixed with premix (a cementitious mixture of portland cement, blast furnace slag, and Class F fly ash) in a 10-inch Readco-Kurimoto continuous mixer to produce fresh (uncured) saltstone slurry that is transferred to the Saltstone Disposal Facility (SDF) for permanent disposition in the Saltstone Disposal Units (SDU) (previously referred to a vaults).

The 10-inch Readco-Kurimoto mixer installed in the SPF is a continuous co-rotating twin-screw mixer. The co-rotating shafts contain multiple intermeshing lens-shaped mixing paddles that have tight clearances between the paddles and the inside diameter of the barrel which promotes a "selfwiping" capability. Also on the shafts are augers that provide the flow of premix into the paddles and they also have the tight clearance between the outside flight diameter and barrel. For the wear testing, a 2-inch Readco-Kurimoto continuous co-rotating twin-screw mixer was used and it is geometrically scaled to the 10-inch mixer. The augers and mixing paddles are placed on each shaft at specific stages, with the augers being at stage 1 and the first set of paddles after the augers are at stage 2. This report focuses on the paddle configuration for the mixer that was removed from service in 2011 to install a new mixer as part of Enhanced Low Activity Waste Disposal (ELAWD). The testing in the report was performed on the previous mixer design (removed in 2011) to establish a baseline and to ensure that the wear issues can be duplicated before changing mixer designs.

In March 2011, dry feeds began backing up in the chute that feeds the 10-inch Readco-Kurimoto continuous mixer. The dry feeds were setting off both the 2 foot and the 7 foot indicators in the premix chute to the 10-inch mixer during multiple days of processing. When the 7 foot indicator is tripped, the SPF enters into shutdown. During troubleshooting of the process, the 10-inch mixer was cleaned, inspected and wear was found in the area where the screw augers and the first set of mixing paddles meet. The wear on the paddles eliminated the self-cleaning capabilities of the paddles and augers, leading to a build-up of grout between the paddles/augers and the barrel. This build-up acts as a restricting orifice which reduces the throughput capabilities of the premix as provided by the auger section of the mixer.

For this testing, a soft metal with low wear resistance (6000 series aluminum), was used to minimize run time while maximizing wear rate. Two paddle configurations were tested, with the first four paddles after the augers replaced by the wear paddles. The first configuration was all flat paddles, with the first paddle not aligned with the augers and is consistent with present SPF mixer. The second configuration had helical paddles for the first three stages after the augers and a flat paddle at the fourth stage. The first helical paddle was aligned with the auger flight for the second configuration.

The all flat paddle configuration wear rate was approximately double the wear rate of the helical paddles for the first two sets of paddles after the augers. For both configurations, there was little or no wear on the third and fourth paddle sets based on mass change, indicating that the fully wetted premix materials are much less abrasive than the un-wetted or partially wetted premix. Additionally, inspection of the wear surface of the paddles at higher magnification showed the flat paddles were worn much more than the helical and is consistent with the wear rates. Aligning the auger discharge flight with the first set of helical paddles was effective in reducing the wear rate as compared to the flat paddle configuration. 
Changing the paddle configuration from flat to helical resulted in a slight increase in rheological properties. Although, both tests produced grout-like material that is within the processing rage of the SPF, it should be noted that cement is not included in the premix and water was used rather than salt solution, which does affect the rheology of the fresh grout. The higher rheological properties from the helical wear test are most likely due to the reduced number of shearing paddles in the mixer. In addition, there is variation in the rheological data for each wear test. This is most likely due to the way that the dry feeds enter the mixer from the dry feeder. The premix is discharged from the hopper in an unsteady fashion, where irregular sized clumps were observed leaving the discharge of the auger, though the auger speed is constant.

Based on the conclusions of this report and the report that investigated alternate materials of construction for the mixer paddles ${ }^{2}$, the lifetime of the mixer in the SPF can be extended if the helical and flat paddles are strategically placed along the mixer shafts and highly wear resistant materials are used for the paddles. Since the new mixer is already installed, these changes should be implemented in the spare mixer. Recommendations for further wear testing include:

- Testing the current ELAWD mixer configuration with current and recommended paddle configurations

- Use wear paddles as part of other testing using the scaled Saltstone Facility

- $\quad$ Reduce the mixer speed to determine the impact on paddle wear 


\section{TABLE OF CONTENTS}

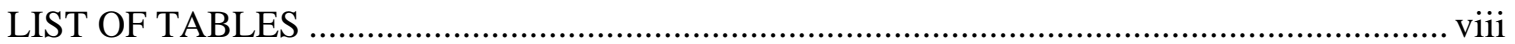

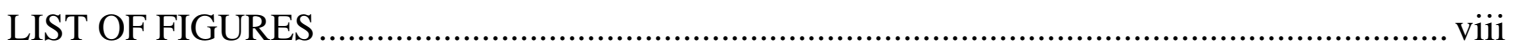

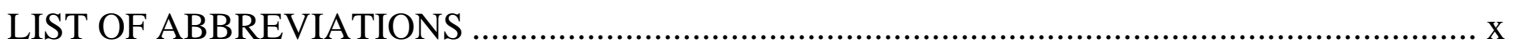

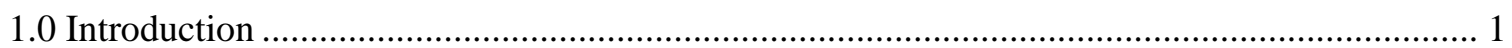

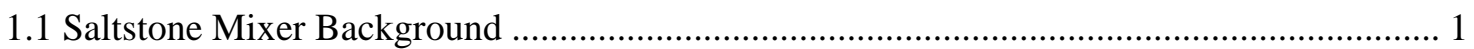

1.2 Comparison of Readco-Kurimoto Continuous Mixers ......................................................... 5

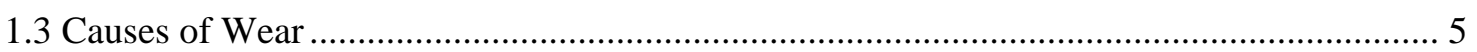

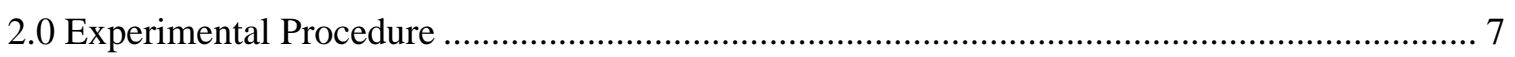

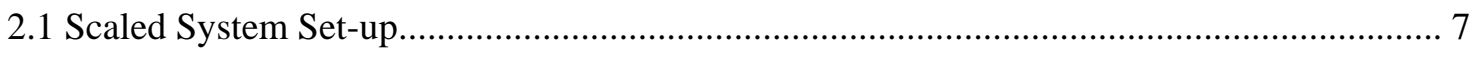

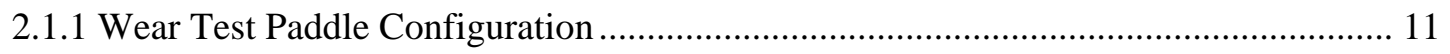

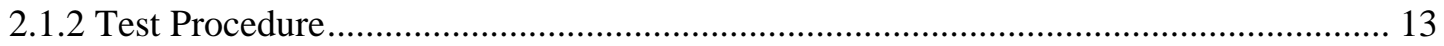

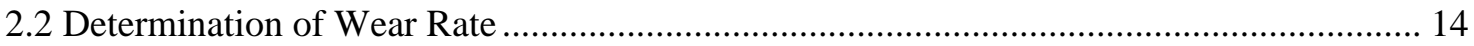

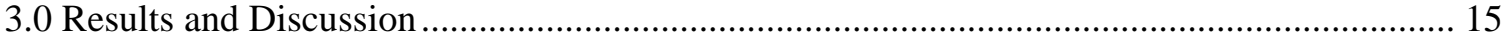

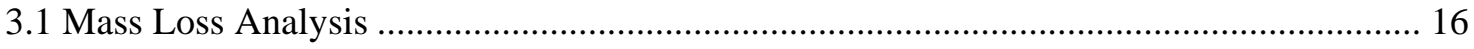

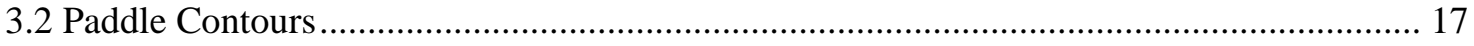

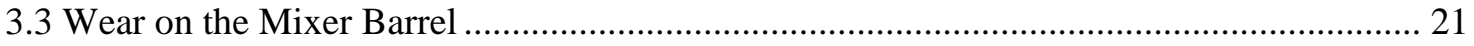

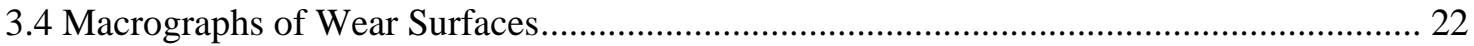

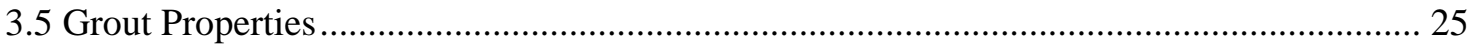

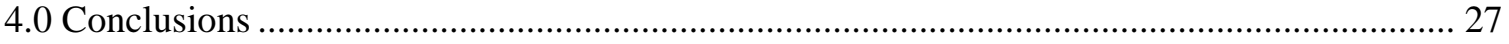

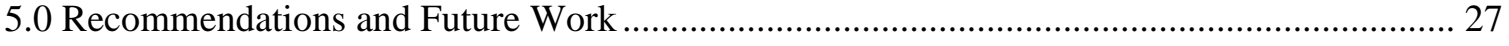

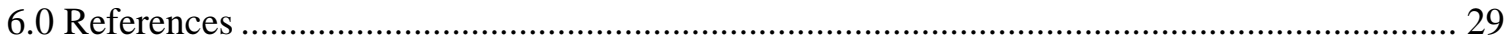




\section{LIST OF TABLES}

Table 1-1. Measurements taken during mixer inspections in September 2010 and May $2011^{6} \ldots . . . .3$

Table 1-2. Machined tolerances in the 2-inch and 10-inch Readco-Kurimoto continuous mixers . 3

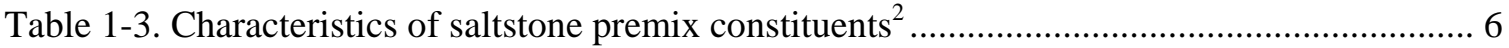

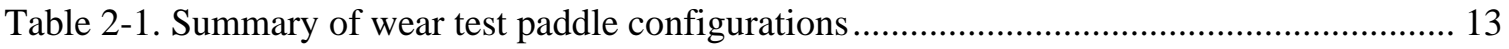

Table 2-2. Testing conditions for the 2 inch mixer compared to the 10 inch mixer...................... 13

Table 3-1. Wear on the paddle tips for stage 2 and 3 paddles after wear test 1 and $2 \ldots \ldots \ldots \ldots \ldots \ldots . . . . . .20$

Table 3-2. Fresh grout property results for the flat paddle wear test........................................... 25

Table 3-3. Fresh property results for the helical paddle wear test.............................................. 25

\section{LIST OF FIGURES}

Figure 1-1. Inspection of the 10-inch Readco-Kurimoto mixer in the SPF showing (a) all the flat mixer paddles (note the tight clearance between the paddles and barrel), and (b) the misalignment of the auger and the first paddle as well as the wear on the last auger flights and first paddles ${ }^{5,6}$

Figure 1-2. Grout build up at the auger/paddle interface in the saltstone 10 -inch mixer ${ }^{6} \ldots \ldots . . . . . . . . .44$

Figure 1-3. Paddle configuration for first five stages (augers at stage 1) for the ELAWD mixer installed in the SPF in 2012 (note the helical paddles at the second stage and the misalignment with the auger). 5

Figure 2-1. SRNL Pilot Scale Processing Facility as Configured for the Wear Testing ................. 7

Figure 2-2. Schenck Accurate, Inc. Mechatron dry feeder.......................................................... 8

Figure 2-3. Readco Kurimoto 2-inch co-rotating twin-screw continuous mixer assembly............. 8

Figure 2-4. Two types of paddles flat (left) and helical (right) for the Readco-Kurimoto

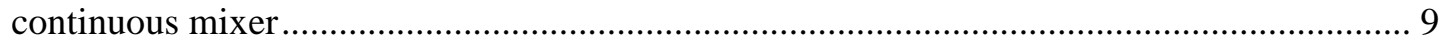

Figure 2-5. Example paddle configurations and orientations for the Readco continuous mixer; all mixing (left) and combination of mixing and conveying (right).......................................... 10

Figure 2-6. Scaled saltstone set up of the dry feeder, 2-inch mixer, and collection vessel used in the paddle configuration wear testing .................................................................................... 11

Figure 2-7. Paddle configurations for wear test 1 (a and c) and wear test 2 (b and d) ................. 12

Figure 2-8. Paddle fixture for measuring critical paddle dimensions .......................................... 14 
Figure 2-9. Paddle angular position for the measuring fixture .................................................. 15

Figure 3-1. Paddle mass loss at each stage after approximately 3.3 hours of testing .................... 16

Figure 3-2. Pre- and post-test contour plot for wear test 1, stage 2 flat paddle on the right shaft. 18

Figure 3-3. Pre- and post-test contour plot for wear test 2, stage 2 helical paddle on right shaft. 19

Figure 3-4. Wear at the junction of the inner barrel diameters.................................................. 21

Figure 3-5. Diagram of paddle rotation relative to the measured wear on the inside of the mixer barrel

Figure 3-6. Macrographs of second stage flat wear paddles after wear test 1 showing damage to the tip and polishing due to wear on the leading edge for (a) paddle 1, front tip (b) paddle 1 , rear tip (c) paddle 5, front tip (d) paddle 5, rear tip................................................................ 23

Figure 3-7. Macrographs of second stage helical wear paddles after wear test 2 showing damage to the tip and polishing due to wear on the leading edge for (a) paddle 9, front tip (b) paddle 9 , rear tip (c) paddle 13, front tip (d) paddle 13, rear tip. 


\section{LIST OF ABBREVIATIONS}

$\begin{array}{ll}\text { ELAWD } & \text { Enhanced Low Activity Waste Disposal } \\ \text { HMI } & \text { Human Machine Interface } \\ \text { lbs } & \text { pounds } \\ \text { LLW } & \text { Low-level waste } \\ \text { rpm } & \text { rotations per minute } \\ \text { SDF } & \text { Saltstone Disposal Facility } \\ \text { SDU } & \text { Saltstone Disposal Unit } \\ \text { SPF } & \text { Saltstone Production Facility } \\ \text { SRNL } & \text { Savannah River National Laboratory } \\ \text { SRS } & \text { Savannah River Site } \\ \text { SS } & \text { 316 L Stainless Steel } \\ \text { WSE } & \text { Waste Solidification Engineering }\end{array}$




\subsection{Introduction}

At the Savannah River Site (SRS), the Saltstone Production Facility (SPF) receives low level waste (LLW) salt solution from Tank $50 \mathrm{H}$ for treatment and disposal. At the SPF, the LLW is mixed with premix (a cementitious mixture of portland cement, blast furnace slag, and Class F fly ash) in a 10-inch Readco-Kurimoto continuous mixer to produce fresh (uncured) saltstone that is transferred to the Saltstone Disposal Facility (SDF) for permanent disposition in the Saltstone Disposal Units (SDU) (previously referred to a vaults).

In March 2011, dry feeds began backing up in the chute that feeds the 10-inch Readco-Kurimoto continuous mixer. The dry feeds were setting off both the 2 foot and the 7 foot indicators in the premix chute to the Readco-Kurimoto mixer during multiple days of processing. When the 7 foot indicator is tripped, the SPF enters into shutdown. During troubleshooting of the process, the Readco-Kurimoto mixer was cleaned and inspected and wear was found in the area where the screw augers and the first set of mixing paddles meet. ${ }^{1}$ The wear to the paddles eliminated the self-cleaning capabilities of the paddles and augers, leading to a build-up of grout between the paddles/augers and the barrel. This build-up acts as an orifice which reduces the throughput capabilities of the premix through the mixer. Waste solidification Engineering (WSE) has tasked Savannah River National Laboratory (SRNL) with investigating the degradation mechanism that causes wear to the paddles, using a 2-inch Readco-Kurimoto continuous mixer, and recommending alternative materials of construction for the mixer paddles; and determining whether a different paddle configuration will minimize wear without affecting the product through the mixer. ${ }^{1}$ The results of the alternative material request are documented elsewhere. ${ }^{2}$ As documented in the Task Technical and Quality Assurance Plan, ${ }^{3}$ the focus of this report is to recommend a paddle configuration that will minimize wear in the 10-inch Readco-Kurimoto mixer in use at the SPF.

\subsection{Saltstone Mixer Background}

To date, two 10-inch mixers have been installed at the SPF. The previous Readco-Kurimoto mixer (1990 - 2003) had both shearing and conveying paddles and had processed approximately five million gallons of salt solution. ${ }^{1}$ However, it was determined that more mixing was required, so the paddle configuration was changed to all flat paddles. ${ }^{4}$ The present Readco-Kurimoto mixer $(2003$ - 2011) processed approximately seven million gallons of LLW salt solution and contains only shearing paddles (Appendix A). ${ }^{1,4}$ It was removed from service in December 2011 and replaced with a new 10-inch Readco-Kurimoto mixer as part of the Enhanced Low Activity Waste Disposal (ELAWD) changes to the SPF. This report focuses on the paddle configuration for the mixer that was removed from service in 2011 to install a new mixer as part of ELAWD.

In the 10-inch mixer recently removed from service, the dry feeds were fed onto the augers which provided the driving force to move the material into the mixer barrel. The LLW salt solution entered the mixer over the first mixing paddles after the augers. ${ }^{5}$ During inspection of the mixer in May 2011, significant wear was found on the last flight of the augers and the first mixing paddles, while the downstream paddles had no visible wear (Figure 1-1). ${ }^{6}$ During this inspection, measurements were taken of the clearances between the mixing elements and the barrel and compared to measurements taken in September 2010 (Table 1-1). ${ }^{6}$ The first two paddles showed a large change in the clearance between the paddle and the barrel, such that the measured spacing is outside the vendor recommended clearances (Table 1-2); however, other paddles further down the mixer had little or no change in the clearance and are within the specified tolerance. 

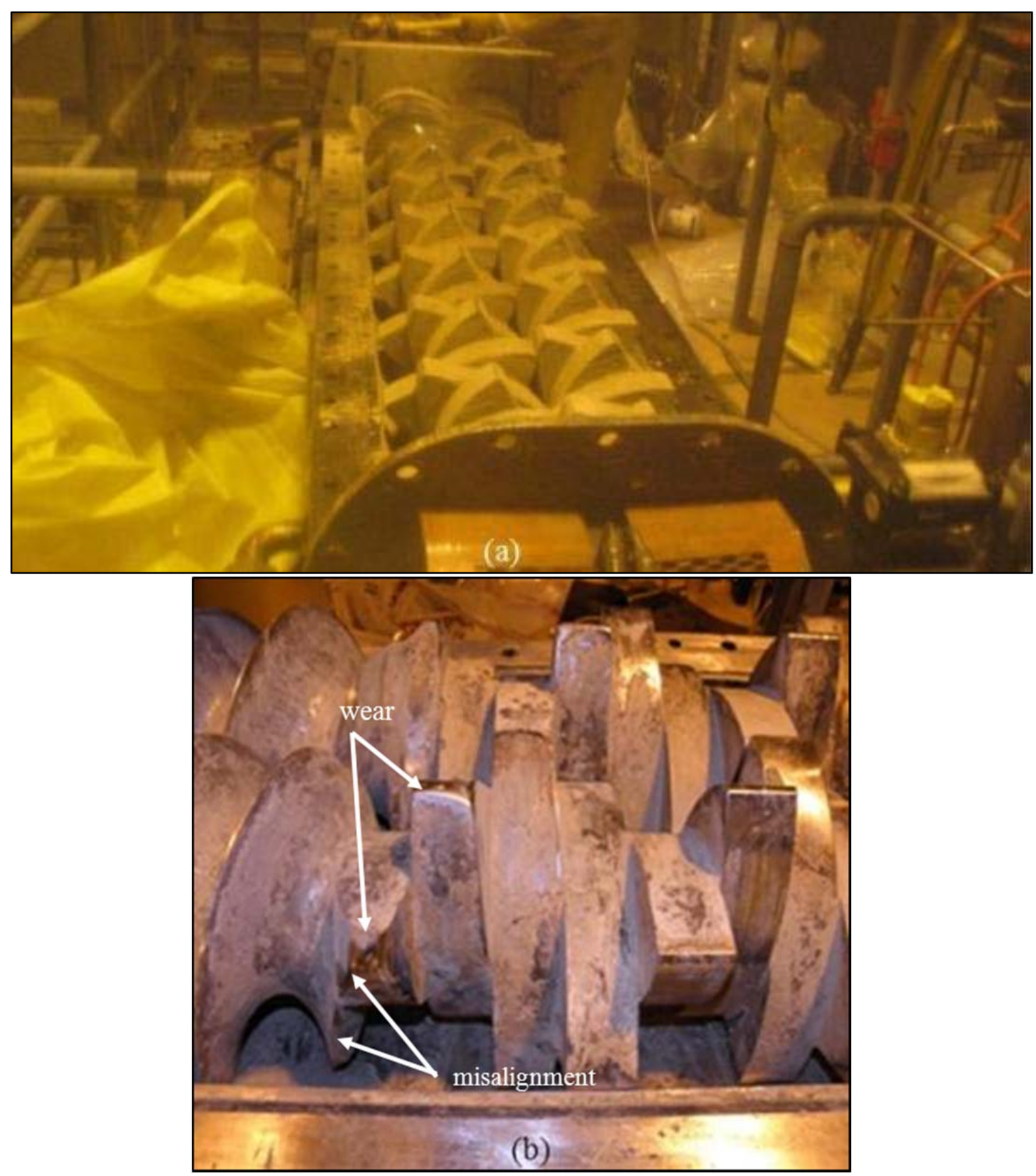

Figure 1-1. Inspection of the 10-inch Readco-Kurimoto mixer in the SPF showing (a) all the flat mixer paddles (note the tight clearance between the paddles and barrel), and (b) the misalignment of the auger and the first paddle as well as the wear on the last auger flights and first paddles ${ }^{5,6}$ 
Table 1-1. Measurements taken during mixer inspections in September 2010 and May $2011^{6}$

\begin{tabular}{|c|c|c|c|c|c|}
\hline \multicolumn{3}{|c|}{ "Mixer Inspection Results 9/14/10 } & \multicolumn{3}{|c|}{ Mixer Inspection Results 5/9/11 } \\
\hline Paddle \# & East & West & Paddle \# & East & West \\
\hline \multicolumn{3}{|c|}{ Tip of Paddle to Barrel (in) } & \multicolumn{3}{|c|}{ Tip of Paddle to Barrel (least wear) (in) } \\
\hline 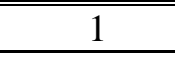 & 0.346 & 0.275 & 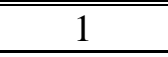 & 0.5 & 0.4375 \\
\hline 2 & 0.13 & 0.148 & 2 & 0.14 & 0.165 \\
\hline 8 & 0.085 & 0.12 & 8 & 0.093 & 0.128 \\
\hline 16 & 0.085 & 0.12 & 16 & 0.091 & 0.128 \\
\hline 27 & 0.085 & 0.105 & 27 & 0.087 & 0.124 \\
\hline 28 & 0.085 & 0.12 & 28 & 0.087 & 0.124 \\
\hline \multicolumn{3}{|c|}{$\begin{array}{c}\text { Tip of Last Auger/Screw to Barrel } \\
\text { (in) }\end{array}$} & \multicolumn{3}{|c|}{$\begin{array}{c}\text { Tip of Last Auger/Screws to Barrel } \\
\text { (least clearance) (in) }\end{array}$} \\
\hline & 0.113 & 0.113 & & 0.12 & 0.113 \\
\hline & & & \multicolumn{3}{|c|}{$\begin{array}{l}\text { Tip of Last/Screw to Barrel at } \\
\text { point of most Wear (in) }\end{array}$} \\
\hline & & & & 1.4375 & 1.375 \\
\hline
\end{tabular}

Continuous co-rotating twin-screw mixers offer multiple advantages over single screw or batch mixers. The continuous mixer has interchangeable parts, making it adaptable to most processes, it produces material at a similar or faster rate than batch processes, and it reduces mixing time while maintaining tight process control and product quality. ${ }^{7,8}$ The co-rotating shafts contain multiple intermeshing lens-shaped mixing paddles that have tight clearances between the paddles and the inside diameter of the barrel (Figure 1-1 a) which promotes a "self-wiping" capability of these mixers. ${ }^{7-9}$ The machined tolerances between the rotating components and the barrel wall of the 2-inch and 10-inch Readco-Kurimoto continuous mixers are provided in Table 1-2. The tight clearances are what form the high shear rate gaps between the co-rotating paddles causing distributive mixing ${ }^{7,9}$ of the premix and salt solution.

Table 1-2. Machined tolerances in the 2-inch and 10-inch Readco-Kurimoto continuous mixers

\begin{tabular}{||c|c|c||}
\hline Clearance Locations & 2-inch Mixer (inches) & 10-inch Mixer (inches) \\
\hline \hline Screw to screw & 0.020 & 0.020 \\
\hline Paddle to paddle & $0.020-0.040$ & $0.095-0.155$ \\
\hline Paddle to barrel wall & $0.020-0.040$ & $0.110-0.145$ \\
\hline Screw to barrel wall & 0.020 & $0.110-0.140$ \\
\hline
\end{tabular}

As shown in Table 1-2, the machined clearances between shaft elements and the inside of the barrel are tightly controlled to maximize the self-wiping capability. Wear on any element that would cause the clearance to be out of the specified range would allow for product buildup since the self-wiping capabilities have been lost. This is especially detrimental in the SPF, since the cementious slurry being processed will set up and harden. Therefore, minimizing wear on the mixing elements is crucial to maintaining throughput and maximizing operational lifetime of the 10-inch mixer. In the mixer removed in 2011, the buildup of cured grout led to the decreased throughput capability of the mixer (Figure 1-2) by creating an orifice at the discharge section of the auger. 


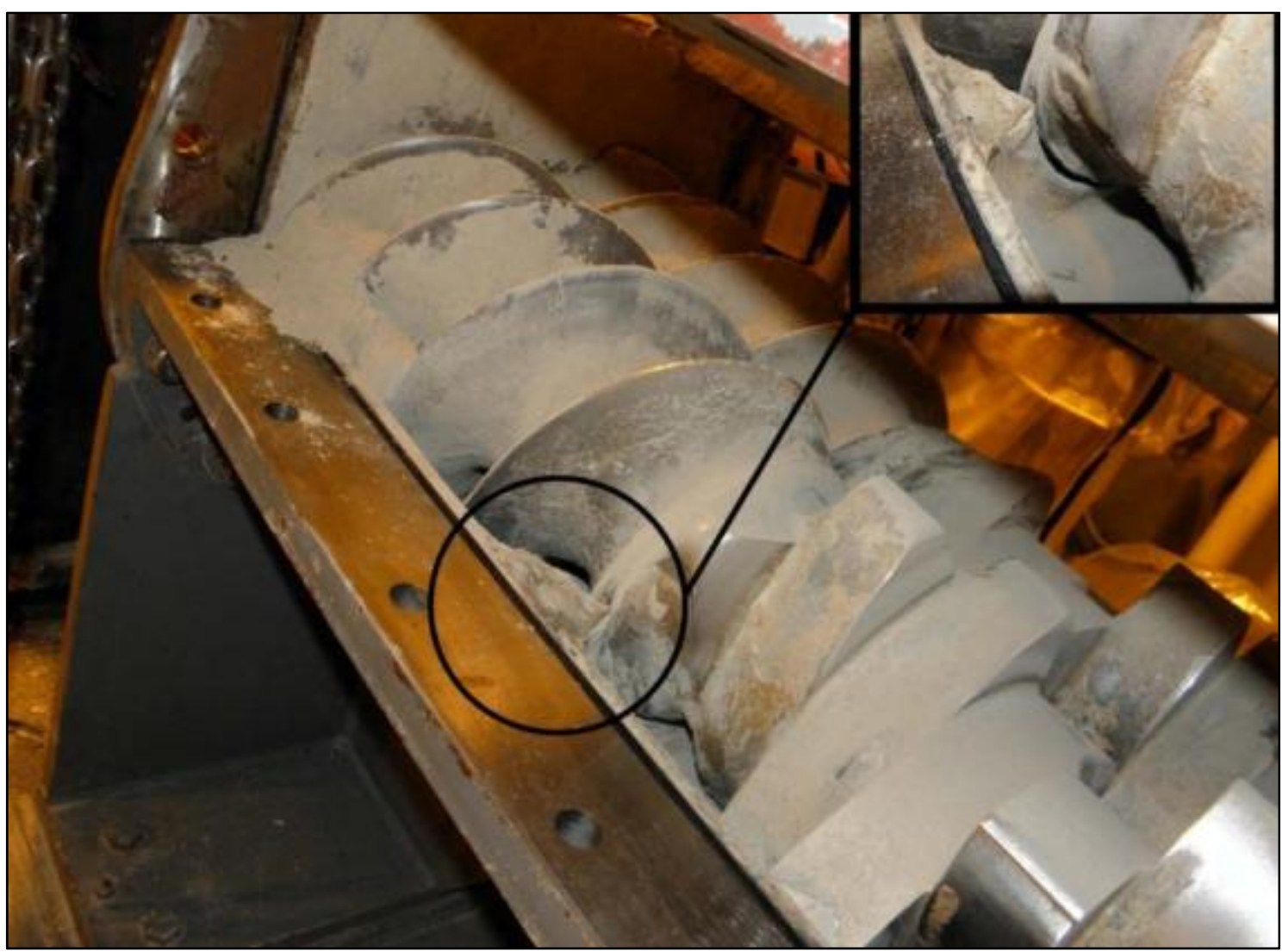

Figure 1-2. Grout build up at the auger/paddle interface in the saltstone 10 -inch mixer ${ }^{6}$

The testing in the report was performed on the previous mixer design (removed in 2011) to establish a baseline and to ensure that the wear issues can be duplicated before changing mixer designs. The mixer installed in 2012 as part of ELAWD (and its identical spare) has a slightly different design than the mixer that was removed from service and tested in this report (Appendix A). The mixer barrel is longer since the auger screws are 24 inches rather than 16 inches while still maintaining the 28 paddles on each mixing shaft. The entrance for the dry feeds is circular rather than rectangular, which moved the liquid inlet over the sixth and seventh stage paddles rather than the second and third stage paddles. Currently, all the paddles are flat, except for stage 2, which is helical; however, it is not aligned with the auger flight (Figure 1-3). 


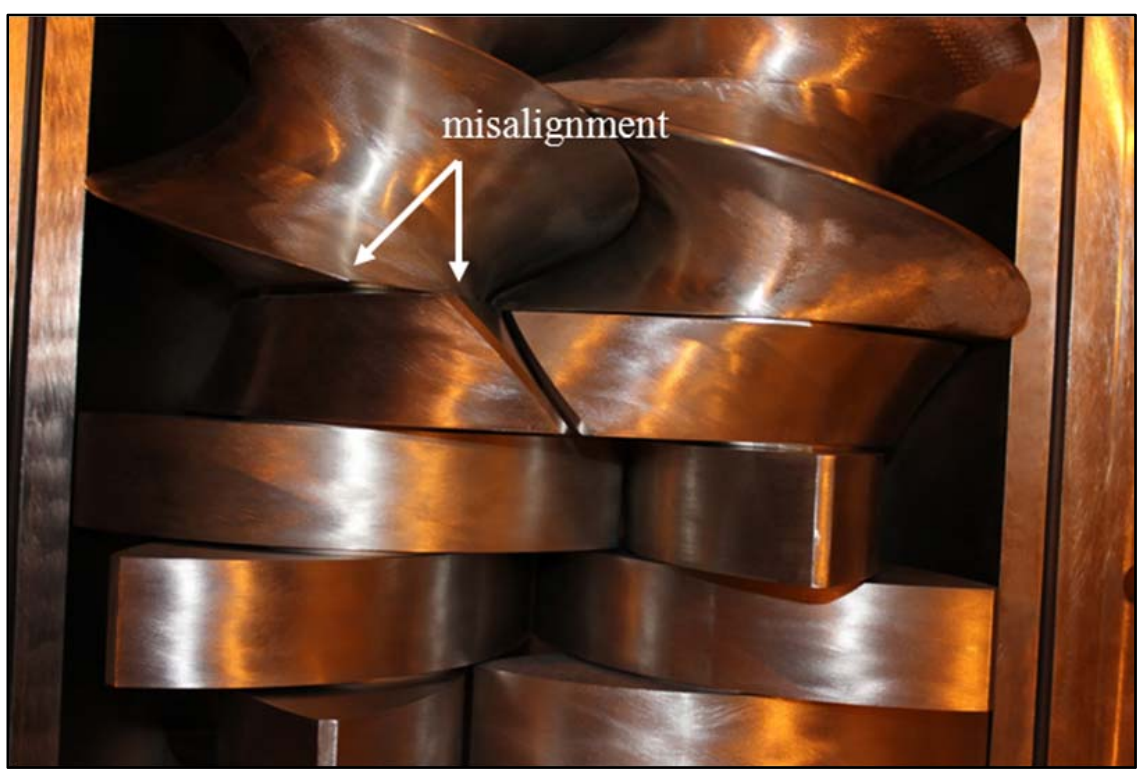

Figure 1-3. Paddle configuration for first five stages (augers at stage 1) for the ELAWD mixer installed in the SPF in 2012 (note the helical paddles at the second stage and the misalignment with the auger).

\subsection{Comparison of Readco-Kurimoto Continuous Mixers}

It is difficult to duplicate the conditions that caused the wear inside the 10-inch continuous mixer installed in the SPF without running the mixer itself. Continuous co-rotating twin-screw mixers are beneficial for a variety of processes because scaling can be done from a small mixer to a larger one. ${ }^{10}$ The scale-up parameters for these types of mixers include residence time, energy input or heat transfer. ${ }^{7,8}$ The ReadcoKurimoto 2-inch and 10-inch continuous mixers are geometrically scaled (dimension and pitch). The geometric scaling also implies that the rotational speed is constant for both the 10-inch and 2-inch mixers, resulting in an average shear rate for both mixers. ${ }^{10}$

The scale-up parameter used was based on energy input (or volumetric throughput). For this testing, the scaling was calculated by assuming the volume is proportional to the cubed internal diameter of the mixer, resulting in the 2-inch mixer being 125 times geometrically smaller than the 10 -inch mixer. ${ }^{8}$ Therefore, the 2-inch mixer has a $1: 125^{*}$ volumetric scale ratio with the 10 -inch mixer installed in the SPF. ${ }^{11}$ The clearances provided in Table 1-2 are geometrically scaled. The 2-inch mixer has the same number of paddle stages as the 10-inch mixer; therefore it can be configured with the same paddle configuration. Therefore, the 2-inch continuous mixer procured by SRNL as part of development of a scaled Saltstone Facility $^{12,13}$ is used for testing alternate paddle configurations for the 10-inch mixer.

\subsection{Causes of Wear}

The wear of the saltstone mixer paddles and augers has resulted from the premix and salt solution slurry movement through the mixer. The wear could be due to corrosion; however, in other testing it was determined that corrosion wear is not the cause of the worn paddles in the saltstone mixer. ${ }^{2}$ Based on the

\footnotetext{
* The vendor also uses internal volume of the mixers to calculate the scale-up ratio. The internal volumes of the 2-inch and 10inch mixers are 47 and $6257 \mathrm{in}^{3}$, respectively, resulting in a scale up ratio of 1:133. Since this ratio results in less volume of premix fed to the mixer, the 1:125 ratio was used for this testing to get maximum throughput of material.
} 
saltstone mixer wear inspections, the wear is most likely due to three body abrasion (between the paddle tip, opposing paddle, or barrel) and erosion. ${ }^{2}$ Slurry erosion (wear) of materials is primarily a function of the materials properties of the abrasive particles as well as the target material, the impact angle of the solids, velocity, and the properties of the carrier fluid. ${ }^{14,15}$ For the saltstone mixer, the abrasive particles are from the premix and the particle properties, primarily hardness, density and shape, all contribute to the wear observed in the saltstone 10 -inch mixer.

The properties of the saltstone premix, ground blast furnace slag (GBFS), fly ash and portland cement, are provided in Table 1-3. ${ }^{2}$ The average hardness is unknown but high hardness particles are present $\left(\mathrm{SiO}_{2}\right.$ and $\left.\mathrm{Al}_{2} \mathrm{O}_{3}\right)^{14}$ that lead to greater abrasion. ${ }^{2}$ Particle sizes are quite small which reduces the overall wear of the premix and slurry. The primarily spherical shape of the fly ash and slag would reduce the overall abrasive effect compared to the angular cement particles. The constituents also have high specific gravities ranging from 2 to 3.15. These higher densities materials can lead to greater wear, especially in abrasion under low stresses. ${ }^{2}$ It has also been shown that the un-wetted premix is more abrasive than when it has been mixed with water or salt solution. ${ }^{2}$

Table 1-3. Characteristics of saltstone premix constituents ${ }^{2}$

\begin{tabular}{|c|c|c|c|c|}
\hline Constituent & $\begin{array}{c}\text { Composition } \\
(\%)\end{array}$ & $\begin{array}{c}\text { Mohs } \\
\text { Hardness } \\
\end{array}$ & $\begin{array}{c}\text { Particle Size } \\
\mu \mathrm{m} \text { (in) }\end{array}$ & $\begin{array}{l}\text { Specific } \\
\text { Gravity }\end{array}$ \\
\hline GBFS & $\begin{array}{c}\mathrm{CaO}(34-43) \\
\mathrm{SiO} 2(27-38) \\
\mathrm{Al} 2 \mathrm{O} 3(7-12) \\
\mathrm{MgO}(7-15) \\
\mathrm{Fe} 2 \mathrm{O} 3(0.2-1.6) \\
\mathrm{MnO}(0.15-0.76) \\
\mathrm{S}(1-1.9)\end{array}$ & $5-6$ & $\begin{array}{c}10.97 \\
(0.00043)\end{array}$ & 2.7-3.1 \\
\hline Fly Ash & $\begin{array}{c}\mathrm{SiO} 2, \text { amorphous (41-58) } \\
\mathrm{SiO} 2 \text {, crystalline (3-7) } \\
\text { Al2O3 (18.1-28.6) } \\
\text { Fe2O3 (3.9-26) } \\
\mathrm{CaO}(0.8-6.0) \\
\mathrm{MgO}(0.7-1.4) \\
\mathrm{TiO} 2(1.0-1.9) \\
\end{array}$ & 7 & $\begin{array}{c}33.15 \\
(0.00131)\end{array}$ & $2-3$ \\
\hline $\begin{array}{l}\text { Portland } \\
\text { Cement }\end{array}$ & $\begin{array}{c}\text { 3CaO.SiO2 (20-70) } \\
\text { 2CaO.SiO2 (10-60) } \\
\text { Ca2(Al,Fe)2O5 (5-15) } \\
\text { CaSO4 (2-10) } \\
\text { 3CaO.Al2O3 (1-15) } \\
\text { CaCO3 (0-20) } \\
\text { MgO (0-4) }\end{array}$ & 9 & $\begin{array}{c}19.42 \\
(0.00077)\end{array}$ & 3.15 \\
\hline
\end{tabular}

In addition to the abrasiveness of the un-wetted premix, the impact angle of the premix onto the mixer paddles, and the velocity of the mixer all contribute to the wear of the paddles. As shown in the previous section, the scaling of the 10-inch to the 2-inch scale was done geometrically. It should be noted that the particle size of the premix is not scaled for this testing. Comparing the particle size to the machined tolerances of the 2-inch and 10-inch mixer (Table 1-2), shows that the 2-inch mixer has a smaller gap for the particles than the 10-inch mixer, which could result in higher wear rates on the 2-inch scale. 


\subsection{Experimental Procedure}

\subsection{Scaled System Set-up}

SRNL has developed a pilot scale system of the SPF at Savannah River Site (SRS) (Figure 2-1). The scaled system consists of a Mechatron "MC" dry feeder coupled to a Readco-Kurimoto 2-inch co-rotating twin-screw continuous processor (mixer) which mixes the dry feeds with liquid supplied by a feed tank. The liquid is pumped into the mixer downstream of the dry feeds. Grout is made from the mixing of the dry feeds (slag and fly ash) with water and is discharged from the end of the mixer into a receipt tank.

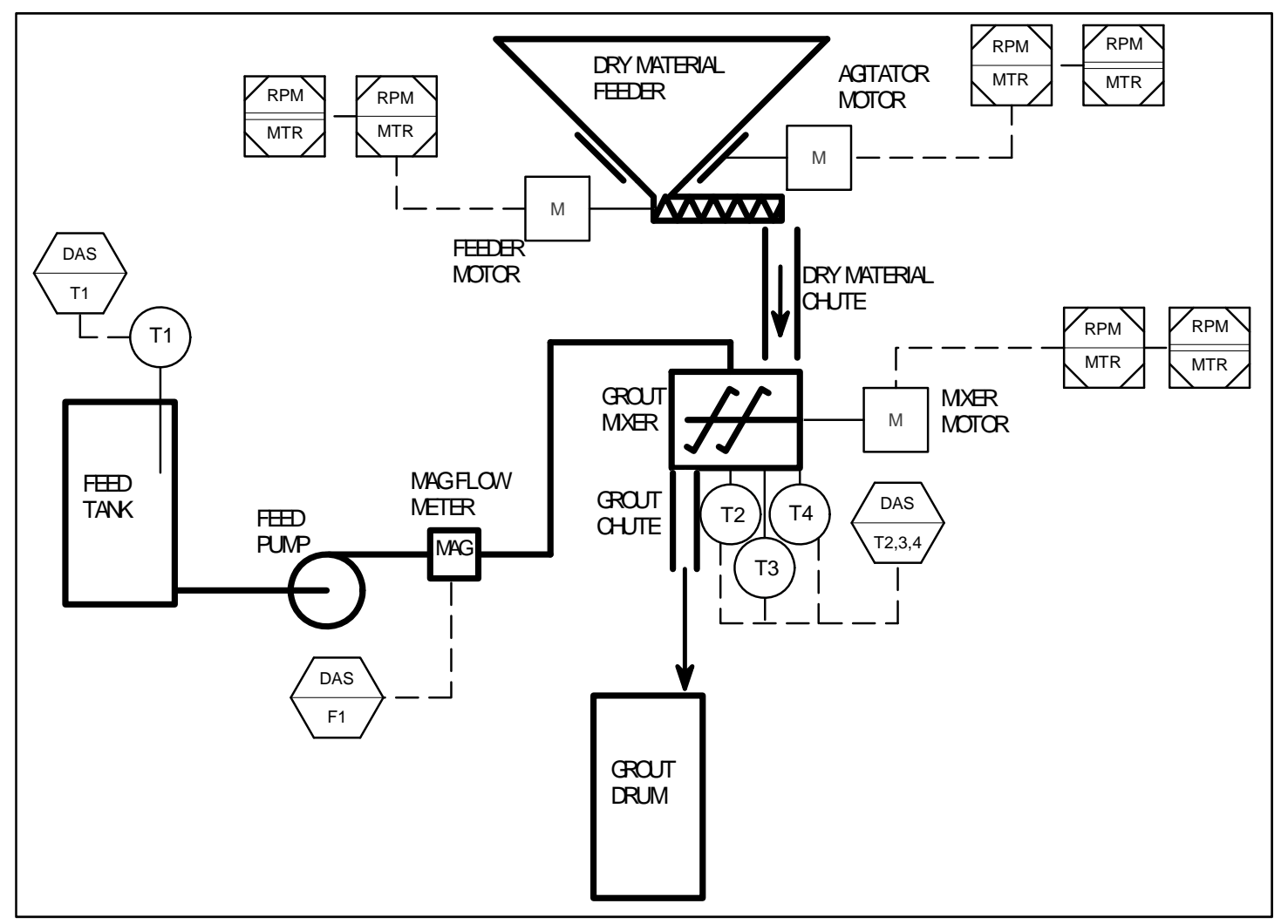

Figure 2-1. SRNL Pilot Scale Processing Facility as Configured for the Wear Testing

The dry material feeder was provided by Schenck Accurate, Inc. The Mechatron ${ }^{\circledR}$ midrange Coni-Flex ${ }^{\mathrm{TM}}$ dual-drive feeder (Figure 2-2) provides a consistent and reliable feed of dry material to the scaled mixer. The feeder discharges dry feed using a 1.73 inch diameter helix auger into the mixer inlet. A drive motor rotates the helix and another drive motor oscillates the agitation paddles on the outside of the flexible hopper. The helix auger is continuously feeding material into the dry feed chute; however, the material disengages from the end of auger in irregular sized clumps. The reason for this is that the slag and premix are not considered free flowing materials due to their particle size. The micron size particles have cohesive (or electro-static) forces that result in clumping flow and by how the discharge of the dry hopper is designed. The agitation paddles are used to mitigate bridging of the dry powders. The speed of each drive motor is variable through the control panel. A hopper extender is attached to the feeder to provide a total hopper volume of 8.7 cubic feet. For the wear testing, the feeder was operated in the volumetric mode; the helix motor was set at a constant speed to provide the required dry feed rate. Prior to testing the dry feed rate was calibrated to obtain a feed rate (mass basis) versus helix speed curve and the speed that provided the necessary mass flow rate was selected. The feed rate was checked as needed to verify the mass flow rate of dry solids. 
SRNL-STI-2012-00549

Revision 0

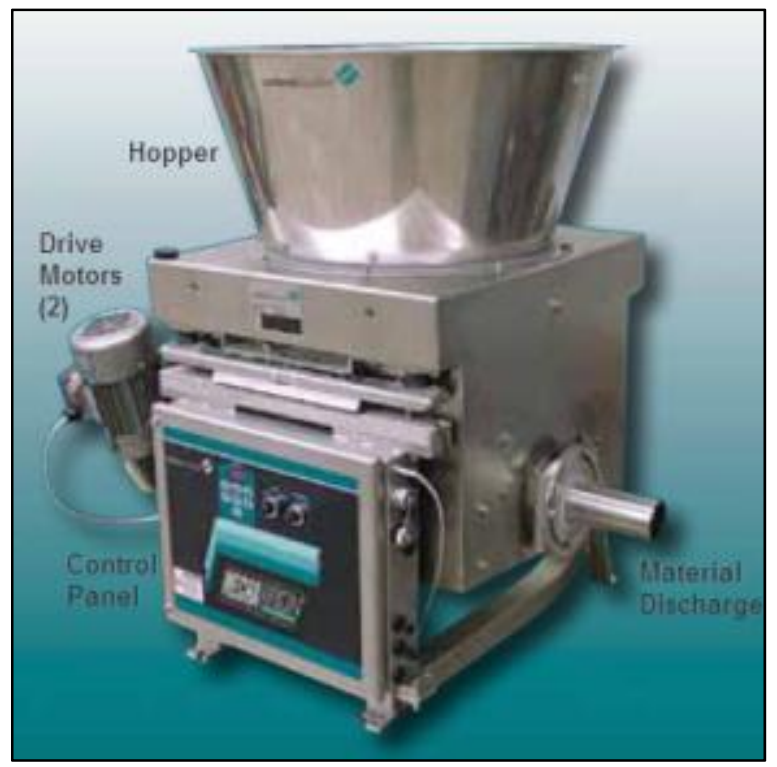

Figure 2-2. Schenck Accurate, Inc. Mechatron dry feeder

The 2-inch co-rotating twin-screw continuous mixer assembly was manufactured by Readco-Kurimoto LLC. The assembly consists of a 5 hp motor, a 1.4:1 ratio gearbox, a Human Machine Interface (HMI) control panel, and the scaled mixer on a sturdy steel frame with castors (Figure 2-3). The mixer is cantilevered from the frame and is level relative to the floor.

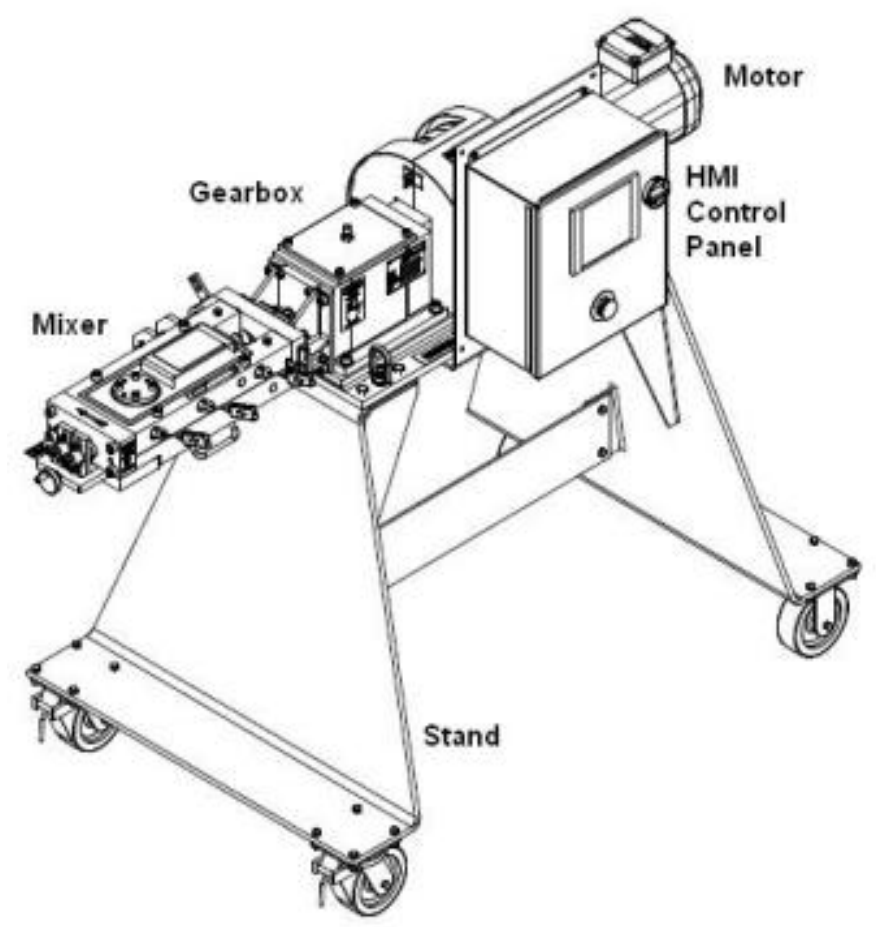

Figure 2-3. Readco Kurimoto 2-inch co-rotating twin-screw continuous mixer assembly 
The Readco-Kurimoto 2-inch twin-screw mixer has co-rotating intermeshing shafts fitted with paddles and integrated screw augers. Each barrel is 2 inches in diameter and 17.38 inches long. The barrels overlapped to produce a figure- 8 cross section. The shafts rotated in the same direction (counterclockwise looking towards the motor) and the paddles of each shaft were aligned to mesh in the overlapping section. A small clearance between meshing paddles and between the paddles and the barrels produced a selfwiping action that minimizes material buildup. The mixing barrel was jacketed to allow for heating or cooling of the product. There are three 3/8 inch NPT threaded ports for liquid addition, thermocouples, or pressure transducers spaced equally along the length of the barrel. The motor speed is variable, controlled through the HMI control panel, with a maximum recommended motor speed of $220 \mathrm{rpm}$. The 2-inch motor has a step-up gear box with a 1.4 to 1 gear ratio, which makes the maximum mixer (paddle/auger) speed 307 rpm.

The shaft design for the 2-inch mixer had 26 stages of mixing elements. The first stage is the inlet auger, which conveys the dry material into the barrels that enclose part of the auger and the mixing paddles. Stages 2 through 26 are occupied by paddles. The paddle configuration on the shaft is variable by changing paddle design and orientation, as defined by the material being processed. There were two types of paddles, a mixing (flat) paddle and a conveying (helical) paddle. Both paddle designs were lens shaped with flat tips (Figure 2-4) and the volumes of each are the same. The flat paddles produced high mixing intensity but no conveying action. The helical paddles produced moderate mixing intensity compared to the flat paddles and low conveying action compared to the auger. The orientation of the paddles on the shaft was adjustable in $45^{\circ}$ increments by means of multiple keyways in the paddle shaft hole (Figure 2-4). The intermeshing dual shafts required that a paddle on one shaft was oriented $90^{\circ}$ with respect to its mating paddle on the other shaft. This allowed each shaft to rotate without obstruction and to maintain the self-wiping action. Two example shaft assemblies are illustrated in Figure 2-5.

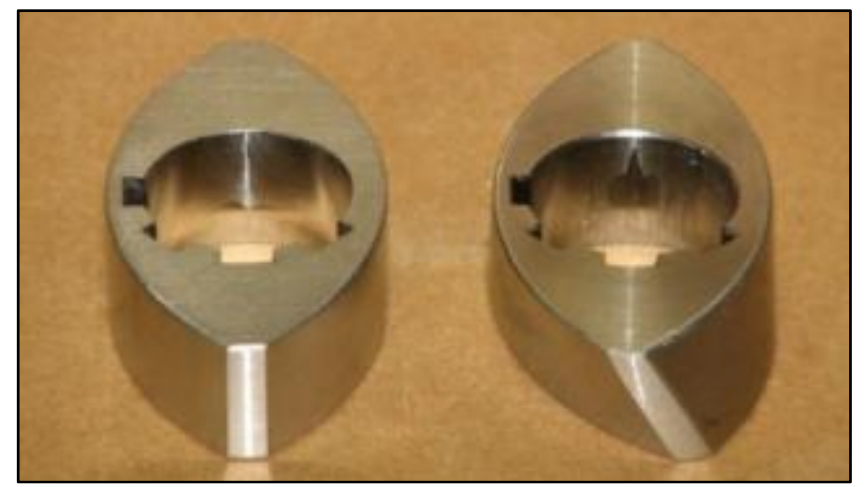

Figure 2-4. Two types of paddles flat (left) and helical (right) for the Readco-Kurimoto continuous mixer 
SRNL-STI-2012-00549

Revision 0
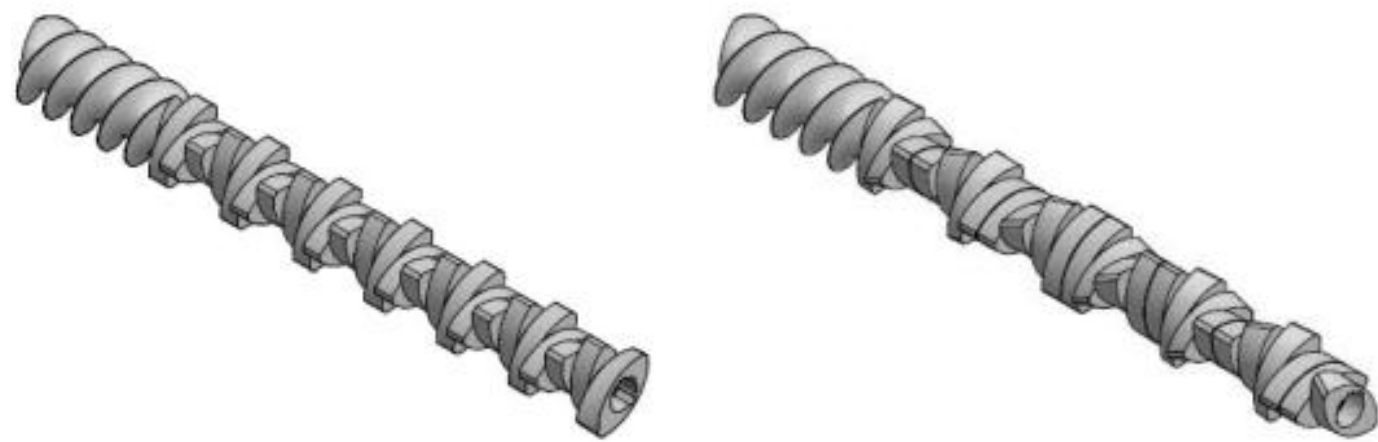

Figure 2-5. Example paddle configurations and orientations for the Readco continuous mixer; all mixing (left) and combination of mixing and conveying (right)

Liquid feed was introduced into the 2-inch mixer above the third stage paddles (second set of mixing paddles after the augers) on the right side (looking towards the motor). For the previously installed 10inch mixer at the SPF, the liquid feed was introduced above the third and fourth stage paddles (second and third set of mixing paddles). Additional equipment included a low capacity liquid feed pump, a liquid feed tank and a grout receipt tank. Both tanks were 55-gallon drums. Instrumentation included a magnetic flow meter in the liquid feed line and 4 thermocouples. One type $\mathrm{K}$ thermocouple monitored the air temperature initially then monitored the liquid feed temperature in later tests. Three type J thermocouples monitored the temperature of the mixer housing in locations along the barrel. The housing is equipped with cavities for forced cooling, but this feature was not used during the relatively short duration wear tests. A Dell Latitude ${ }^{\mathrm{TM}}$ laptop loaded with National Instruments LabVIEW 2009 software recorded the output of the instrumentation during the wear tests. The output was analyzed with Microsoft Excel ${ }^{\mathrm{TM}}$ software.

Other instrumentation and equipment used for the wear test included platform scales to weigh dry material, a precision balance to weigh paddles, a Genie Lift ${ }^{\mathrm{TM}}$ to raise the dry material feeder above the mixer, and a Coppus ${ }^{\circledR}$ blower and HEPA filter to remove dry material dust from the work area. Figure 2-6 shows the actual set up of the dry feeder, 2-inch continuous mixer, and grout receipt vessel as used during testing. 


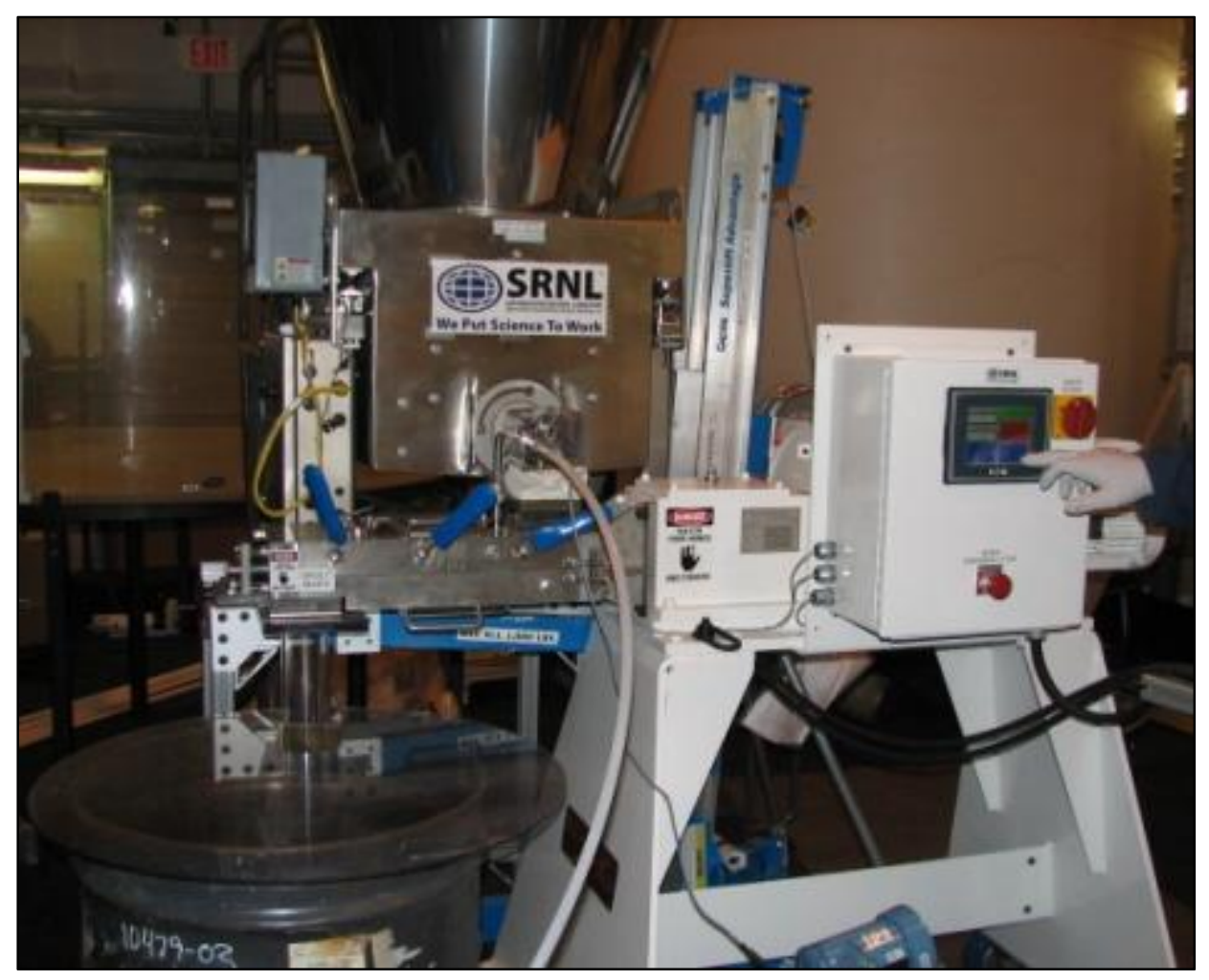

Figure 2-6. Scaled saltstone set up of the dry feeder, 2-inch mixer, and collection vessel used in the paddle configuration wear testing

\subsubsection{Wear Test Paddle Configuration}

Based on the Saltstone 10-inch mixer that was recently removed from service, only the discharged areas of the augers and the first two paddles showed any significant wear (Figure 1-1 b). The downstream paddles had no visible wear; therefore, for both wear tests, the original stainless steel (SS) paddles in stages 2 through 5 were replaced by aluminum wear paddles. The wear paddles were fabricated out of 6000 series aluminum in order to increase the paddle wear rate ${ }^{14}$ and decrease the test run time, since 6000 series aluminum is a soft metal with low wear resistance. Both mixing (flat) and conveyance (helical) paddles were fabricated out of aluminum. Each wear paddle was laser etched with a unique number to aid in reassembly and identification post testing.

Two paddle configurations were tested using the 2-inch mixer. The first paddle configuration tested was the 10-inch mixer configuration in service from 2003 - 2011 (Appendix A). The first stage was the auger followed by flat paddles in stages $2-25$ and ending with a reverse helical paddle in stage 26 . The reverse helical paddle in stage 26 conveyed the grout in the reverse direction away from the seals at the end of the shaft and aided in discharging the grout from the mixer. The flat paddle in stage 2 was at a $45^{\circ}$ angle to the last flight of the auger, creating a discontinuity in the flow path of the dry feeds from the auger into the mixer barrel (Figure 1-1 b and Figure 1-2).

The vendor, Readco-Kurimoto, Inc., recommends the first paddle be aligned with the last auger flight to ensure a smoother transition of dry feeds into the mixer body which results in decreased wear on the first paddle and last auger flight. ${ }^{11}$ In addition, other users of the same continuous mixers have had decreased wear by using helical paddles in the turbulent regions where the dry feeds and liquids initially mix. ${ }^{11}$ 
Therefore, the second paddle configuration tested had the auger in the first stage, stages 2-4 were helical paddles, stages 5-25 were flat paddles and stage 26 was a reverse helical paddle. The helical paddles after the augers (stage 2) were aligned with the auger flights in order to facilitate a smooth transition from the augers into the mixer barrel.

The orientation of the paddles in both configurations was such that each successive paddle was offset $45^{\circ}$, with the sequence repeating itself every fifth paddle (Figure 2-7). The direction of offset was clockwise (looking towards the motor), opposite of shaft rotation. The summary of the differences in the two configurations is listed in Table 2-1.
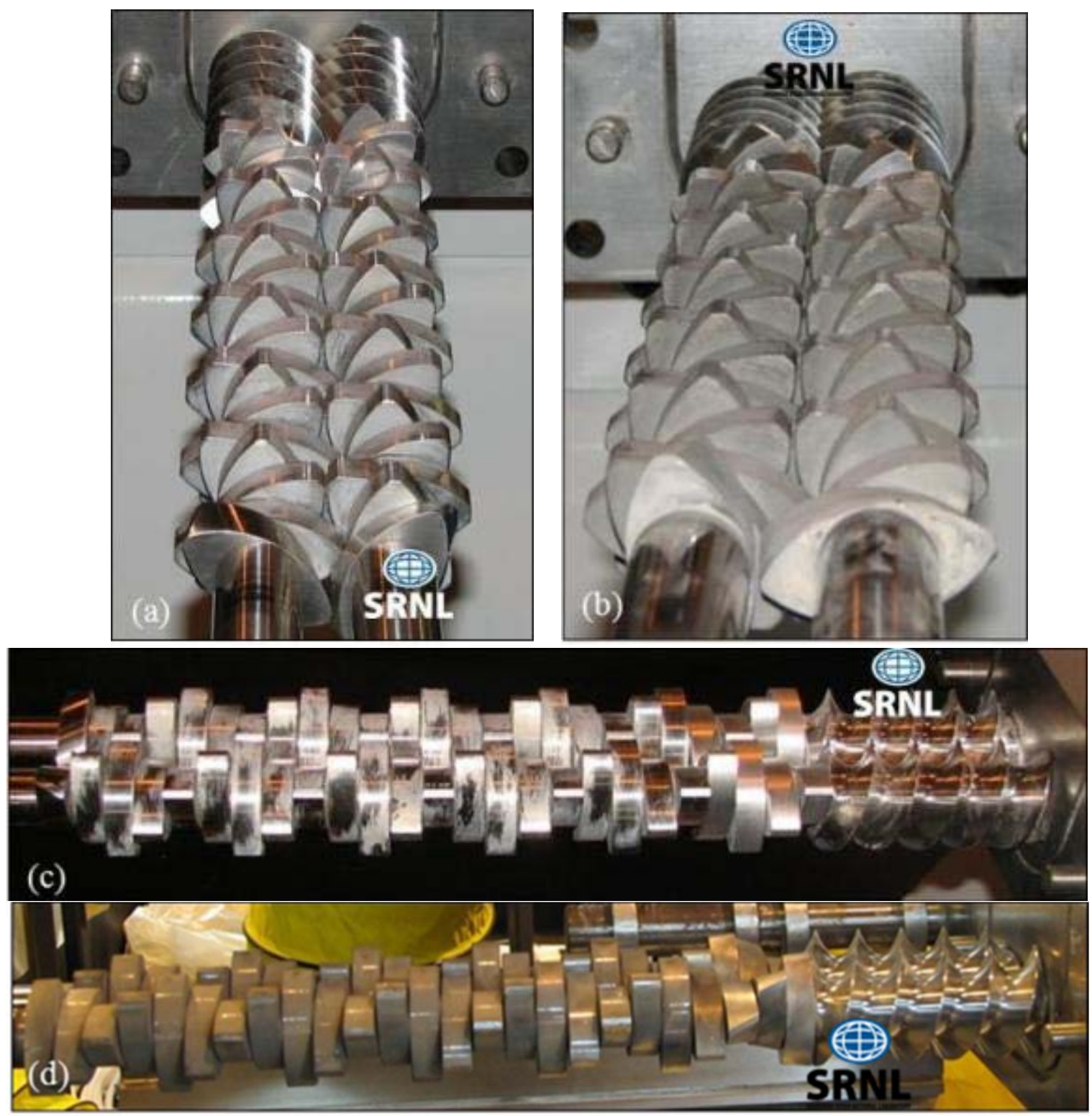

Figure 2-7. Paddle configurations for wear test 1 (a and c) and wear test 2 (b and d) 
Table 2-1. Summary of wear test paddle configurations

\begin{tabular}{|c|c|c|c|c|c|c|c|}
\cline { 2 - 7 } \multicolumn{1}{c|}{} & $\begin{array}{c}\text { Stage } \\
\mathbf{1}\end{array}$ & $\begin{array}{c}\text { Auger/Paddle } \\
\text { Junction }\end{array}$ & $\begin{array}{c}\text { Paddle } \\
\text { Orientation }\end{array}$ & $\begin{array}{c}\text { Stages } \\
\mathbf{2 - 4}\end{array}$ & $\begin{array}{c}\text { Stage } \\
\mathbf{5}\end{array}$ & $\begin{array}{c}\text { Stages } \\
\mathbf{6 - 2 5}\end{array}$ & $\begin{array}{c}\text { Stage } \\
\mathbf{2 6}\end{array}$ \\
\hline \hline Wear & Auger & $\begin{array}{c}\text { Offset } 45^{\circ} \\
\mathrm{CW}^{1}\end{array}$ & $\begin{array}{c}\text { Offset } 45^{\circ} \\
\mathrm{CW}^{*}\end{array}$ & $\begin{array}{c}\text { Flat } \\
\text { Aluminum }\end{array}$ & $\begin{array}{c}\text { Flat } \\
\text { Aluminum }\end{array}$ & Flat SS & $\begin{array}{c}\text { Helical } \\
\text { SS }\end{array}$ \\
\hline $\begin{array}{c}\text { Test 1 } \\
\text { Wear }\end{array}$ & Auger & Aligned & $\begin{array}{c}\text { Offset } 45^{\circ} \\
\mathrm{CW}^{*}\end{array}$ & $\begin{array}{c}\text { Helical } \\
\text { Aluminum }\end{array}$ & $\begin{array}{c}\text { Flat } \\
\text { Aluminum }\end{array}$ & Flat SS & $\begin{array}{c}\text { Helical } \\
\text { SS }\end{array}$ \\
\hline
\end{tabular}

* Looking towards motor.

\subsubsection{Test Procedure}

The testing procedure started by filling the liquid feed tank and loading the dry feed hopper. The dry feed for the wear testing was a mixture of $50 \mathrm{wt} \%$ fly ash and $50 \mathrm{wt} \%$ blast furnace slag. Cement was not used in the dry feeds to avoid corrosion of the aluminum test paddles. In addition, the materials of construction testing showed that corrosion wear is not causing the wear in the saltstone 10-inch mixer, which reinforces not including cement in the premix for this testing. ${ }^{2}$ Approximately 50 gallons of process water and $400 \mathrm{lbs}$ of dry material were loaded into their respective vessels. Dry material was loaded into eight heavy ply plastic bags (50 pounds each), which were palletized and lifted to the top of the feeder using a fork truck. Each bag was emptied into the feed hopper. The $400 \mathrm{lbs}$ of dry material filled the 8.7 cubic foot hopper to the top. The SPF operates at a dry feed throughput of approximately 35 tons/hour with the maximum throughput capacity of 50 tons/hr. For this testing, the dry feeder was run at a dry feed rate comparable to the maximum throughput capacity of the 10 -inch mixer $^{5}$ (Table 2-2).

The liquid feed was started followed by the 2-inch mixer and both were adjusted to their respective test conditions (Table 2-2). The liquid feed rate was maintained to produce a 0.60 water to premix ratio slurry, similar to SPF operations. The 2-inch motor speed was set to $220 \mathrm{rpm}$ (307 rpm mixer speed) to provide maximum throughput for this testing. Grout production started when the dry material feeder was started. Based on the run conditions in Table 2-2, each $400 \mathrm{lb}$ batch of dry material lasted for approximately half an hour.

Table 2-2. Testing conditions for the $\mathbf{2}$ inch mixer compared to the 10 inch mixer

\begin{tabular}{|c|c|c||}
\hline Operating Parameter & 10-inch & 2-inch \\
\hline \hline Maximum dry feed rate (lbs/hr) & 100,000 & 833.3 \\
\hline Mixer (paddle/auger) speed (rpm) & 232 & 307 \\
\hline Target w/p ratio & $0.60 \pm 0.01$ & $0.60 \pm 0.01$ \\
\hline
\end{tabular}

During each half-hour grout run, at least one sample of the slurry was taken at the discharge of the mixer. Fresh properties; rheological flow curve, and flowability were measured for each sample. Rheological flow curves were obtained using a Haake VT550 rotoviscometer equipped with a stationary sample cup and a rotating MVII bob. This instrument is a smooth wall coaxial cylindrical geometry. ${ }^{16,17}$ The flow between the two concentric cylinders is characterized by measuring the torque and rotational speed of the inner cylinder. The torque readings were converted to shear stress and the speed to shear rate. Flow curves (up and down) were generated over a shear rate range of 0 to $300 \mathrm{sec}^{-1}$. Each curve took 150 seconds to accelerate/decelerate. After accelerating to $300 \mathrm{sec}^{-1}$, the shear rate was held for 30 seconds prior to decelerating. The down curves for saltstone grouts have been typically analyzed due to their thixotropic properties and fitted to a Bingham Plastic rheological model. The Bingham Plastic equation used to calculate the plastic viscosity and yield stress using the flow curve data are presented elsewhere. ${ }^{17}$ 
A modified slump test was used to measure the flowability of the fresh saltstone. ${ }^{18}$ Immediately after mixing, the slurry is poured into an open cylinder with one end sitting on a smooth, flat surface. The cylinder is 1.75 by 3 inches and it is fully filled until the slurry almost overflows the top. Approximately 30 seconds after the cylinder was filled, it was lifted vertically approximately one inch off the surface to let the grout flow out under gravity. The diameter of the flowed grout was measured approximately 30 seconds after all the material had discharged from the cylinder.

At the dry feed rate of $833.3 \mathrm{lbs} / \mathrm{hr}$ a full hopper lasted about 30 minutes. Due to the complexity of the reloading process, the system was shut down to assure personnel safety. The shut-down procedure reverses the startup process. The dry feeder was stopped, then after a moment the mixer, and after another moment the liquid feed. The liquid feed was allowed to run for approximately two minutes after stopping the dry feed to flush the majority of the grout out of the mixer. The filling, running, and stopping procedure were repeated until desired run time was reached. Once the test was completed, the system was put into a safe condition and the mixer was opened to remove the paddles for inspection. The mixer housing opens like a clamshell to fully expose the shaft for inspection, cleaning, or paddle replacement.

Following a test the paddles were cleaned before inspection to remove residue. Residue complicated the assessment of mass loss. Typical cleaning involved washing the paddles with warm water and a mild detergent. At times, scrubbing with a plastic brush was required. However, in some cases a more thorough cleaning method was required to remove stubborn residue. Stubborn residue was removed by soaking the paddles in concentrated nitric acid for 2 minutes. This process was carefully evaluated to verify residue removal with minimal aluminum removal. Numerous tests revealed that the aluminum lost during this process was relatively insignificant ( $>0.001$ grams) while the majority of the residue was removed.

\subsection{Determination of Wear Rate}

The critical dimensions of each paddle were measured prior to being placed on the mixer shafts. The critical paddle dimensions were measured using a micrometer and a rotary table (Figure 2-8).

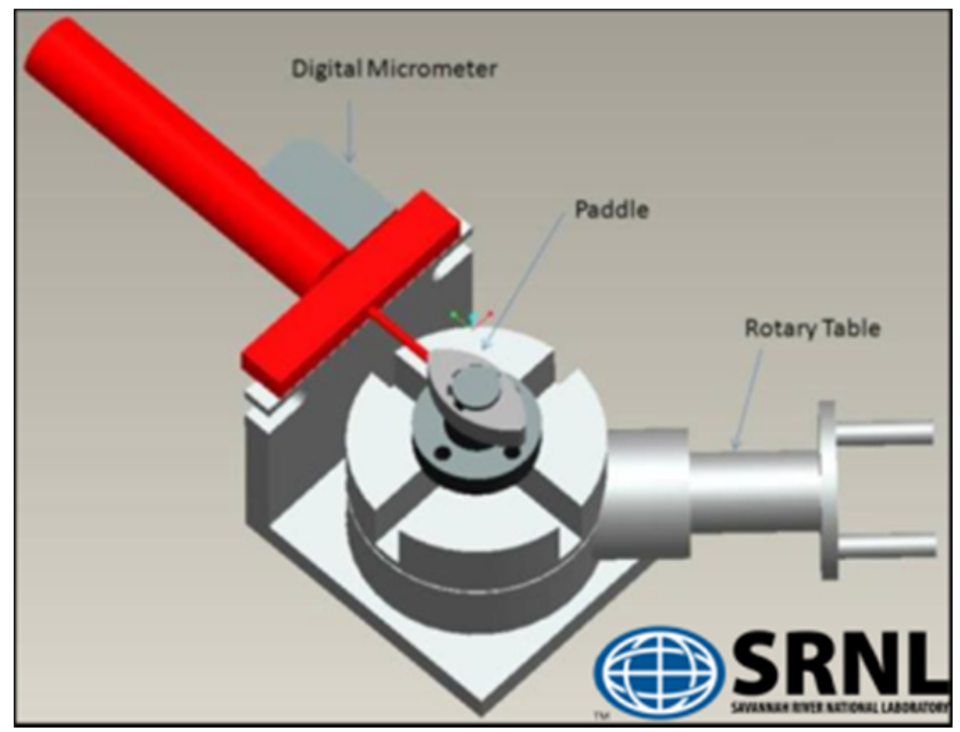

Figure 2-8. Paddle fixture for measuring critical paddle dimensions

\footnotetext{
* Designed by Kevin Hera of SRNL EES/EED
} 
The paddle fixture measured the radial dimension of the paddle contour at various angular locations around the paddle. Figure 2-9 defines the angular position relative to the paddle contour. Readings were concentrated around the tips ( 90 and $270^{\circ}$ ) since it was expected that the majority of the wear would occur in those locations. The micrometer was zeroed on the fixture shaft and the micrometer reading plus the shaft radius provided the radial dimension of the paddle. The radial dimension and the angular location provided polar coordinates that defined the contour of the paddle. The polar coordinates were translated to Cartesian coordinates and plotted to provide before and after comparisons.

The uncertainty of the micrometer is $+/-0.0006$ inches. The uncertainty of the radial measurement due to the rotary table was determined by comparing multiple measurements of the same paddle over a time period spanning the tests. At angular locations where the micrometer plunger was normal or nearly normal to the paddle surface (tips and sides) the uncertainty was +/-0.005 inches. At angular locations where the micrometer plunger was contacting the surface at a steep slope (sides around either tip) the uncertainty was $+/-0.010$ inches.

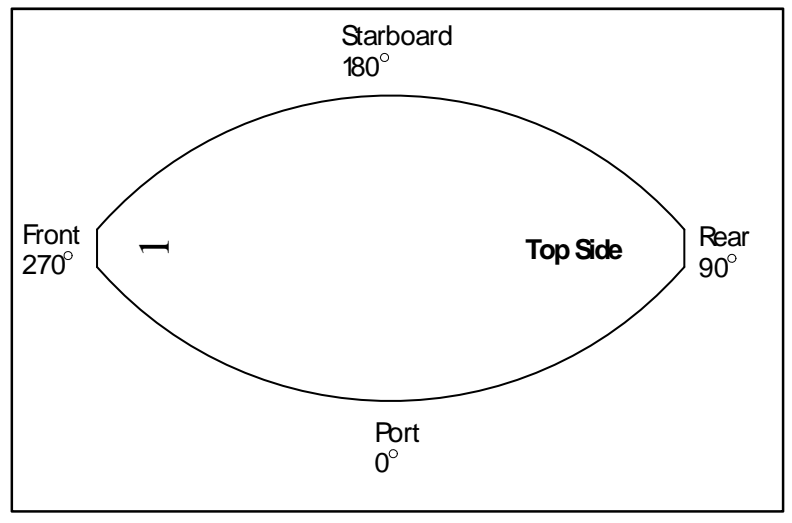

Figure 2-9. Paddle angular position for the measuring fixture

The mass of each paddle was measured with a precision balance before and after each test to quantify the amount of mass lost. Prior to weighing, the paddles were cleaned with warm water and a mild detergent to remove oil or grime and then dried with a towel. The uncertainty of the precision balance was $+/-$ 0.0006 grams. Prior to each use the balance was checked with a calibrated weight set to verify that its response was within the stated accuracy. Given the tolerance of the precision balance and the assessment of aluminum lost during the cleaning process, the uncertainty of the mass measurement was estimated to be $+/-0.002$ grams.

A photograph of each wear paddle was taken before and after testing using a digital camera. In addition, after the testing was complete, macrographs were taken with a Nikon SMZ1500 stereomicroscope with a digital camera attached to record the surface of each aluminum paddle. Macrographs of an untested aluminum paddle were also taken as a reference.

\subsection{Results and Discussion}

Two wear tests were conducted to investigate auger/paddle wear and to investigate a method of reducing mixer wear. The first test (wear test 1 ) had a paddle configuration similar to the 10-inch mixer in the Saltstone facility. This test established baseline wear. The second test (wear test 2) had a reconfigured paddle arrangement that replaced the stage 2-5 flat paddles with helical paddles and aligned the stage 2 paddles with the augers. The intent of the reconfigurations was to more effectively convey the dry material into the region of liquid feed where paddle wear is reduced due to the lubricating effects of the liquid feed. The alignment with the auger provides a smoother transition (minimizing the discontinuity 
between the auger and initial set of paddles which were noted to have the most wear) into the paddles and the helical paddles provides conveyance from the auger to the liquid feed inlet.

The total duration of each wear test was mainly dependent on the amount of dry material that was available. Wear test 1 had a total duration of 3.2 hours and processed approximately 2620 lbs of dry material; wear test 2 had a total duration of 4.1 hours and processed approximately 3300 lbs of dry material. Both tests were run in two phases with paddle inspections at the beginning, the mid-phase, and the end of the tests. The mid-phase of wear test 1 was at 2.3 hours; the mid-phase of wear test 2 was at 3.4 hours. The mid-phase of wear test 2 approximately corresponded to the total run time of Wear Test 1 to provide a direct comparison.

\subsection{Mass Loss Analysis}

The majority of the mass loss occurred in the second stage paddles for both wear tests 1 and 2.The second stage paddles are directly upstream of the liquid feed inlet, which enters the barrel above the stage 3 paddle on the right side (looking towards the motor). The stage 2 area is where the dry feed transitions from dry to wet and is also the transition between the auger and $1^{\text {st }}$ set of paddles. Figure 3-1 shows the actual mass loss of the stage 2-5 paddles in wear test 1 and wear test 2 after approximately 3.3 hours (total run time of wear test 1 versus the mid-phase run time of wear test 2).

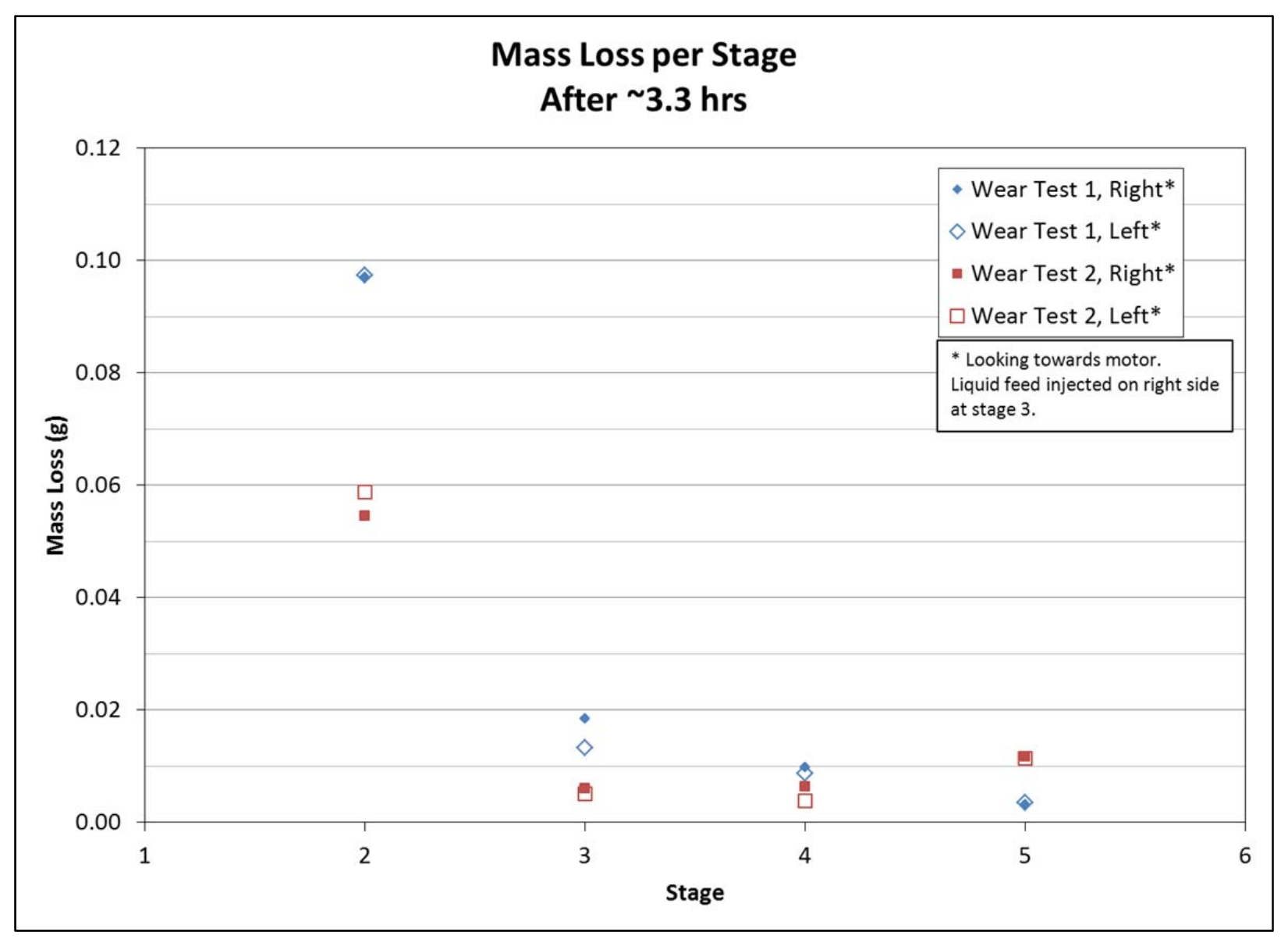

Figure 3-1. Paddle mass loss at each stage after approximately 3.3 hours of testing

As shown in Figure 3-1, the paddle mass loss at stage 2 is approximately $40 \%$ less than the mass loss of the paddles at the same location in wear test 1. It is hypothesized that this is primarily due to the 
misalignment of the second stage paddles with the augers. Also, the dry feeds are more abrasive than the premix-water slurry and the augers and second stage paddles would be more exposed to un-wetted dry feeds than any of the other stages in the mixer.

The mass loss of the third stage paddles (where the liquid feed enters the mixer) was approximately $50 \%$ less for wear test 2 than test 1 . At this stage in the mixer, the slurry has not been subjected to a lot of shear, so the material will be more viscous at the second and third stage than at stage 26 where it is discharged from the mixer. The flat paddles used in wear test 1 are designed to shear rather than convey material, so the viscous slurry has no directional force to move through the mixer other than additional material supplied by the augers. Therefore, it can be assumed the viscous mixture would reside in that location longer, causing more wear, than it would if a helical (conveying) paddle replaced the flat paddle. For wear test 2, it is hypothesized that the viscous mixture is conveyed past the liquid inlet by the helical paddles, reducing the contact time with the paddles, resulting in a lower mass loss. The paddles at stage four had comparable mass loss for both tests. The paddles at stage 5 for wear test 1 had almost no mass loss. For wear test 2, the paddle at stage 5 showed a greater mass loss relative to stage 4 for wear test 2 . This is likely because stage 5 was the transition point from the helical paddle design to the flat paddle design in wear test 2.

In addition, the third stage paddles had minimal mass loss compared to the second stage paddles during the same wear test.

Paddle mass measurement was conducted systematically to reduce measurement uncertainty. The precision balance was checked with a calibrated weight set before each set of measurements. In addition the paddles were washed with a mild detergent to remove oil and grime in the same manner prior to the measurements. Nevertheless, inconsistencies arose in the measurements that required resolution.

\subsection{Paddle Contours}

When the mixer was opened at the end of wear test 1 , a significant amount of wear had visibly occurred at the tips of the stage 2 paddles and a lesser but noticeable amount of wear occurred on the stage 3 paddles. The post-test paddle contours were plotted and, when compared to the pre-test contours, established a baseline wear pattern. Wear test 2 was then conducted with a different paddle configuration. The pretest and post -test paddle contours were plotted and compared to the results of wear test 1 .

The contour plots confirmed that a greater amount of wear occurred on the first wear test flat paddles. The extent of tip wear for the second stage paddle on the right shaft from wear test 1 is shown in Figure 3-2. The second stage paddle on the right shaft from wear test 2 is shown in Figure 3-3. Shown are the pretest and post-test contours. The contour in Figure 3-2 was measured at the middle height of the paddle; the contour in Figure 3-3 was measured at the upper height. These heights represent the location of greatest wear. 


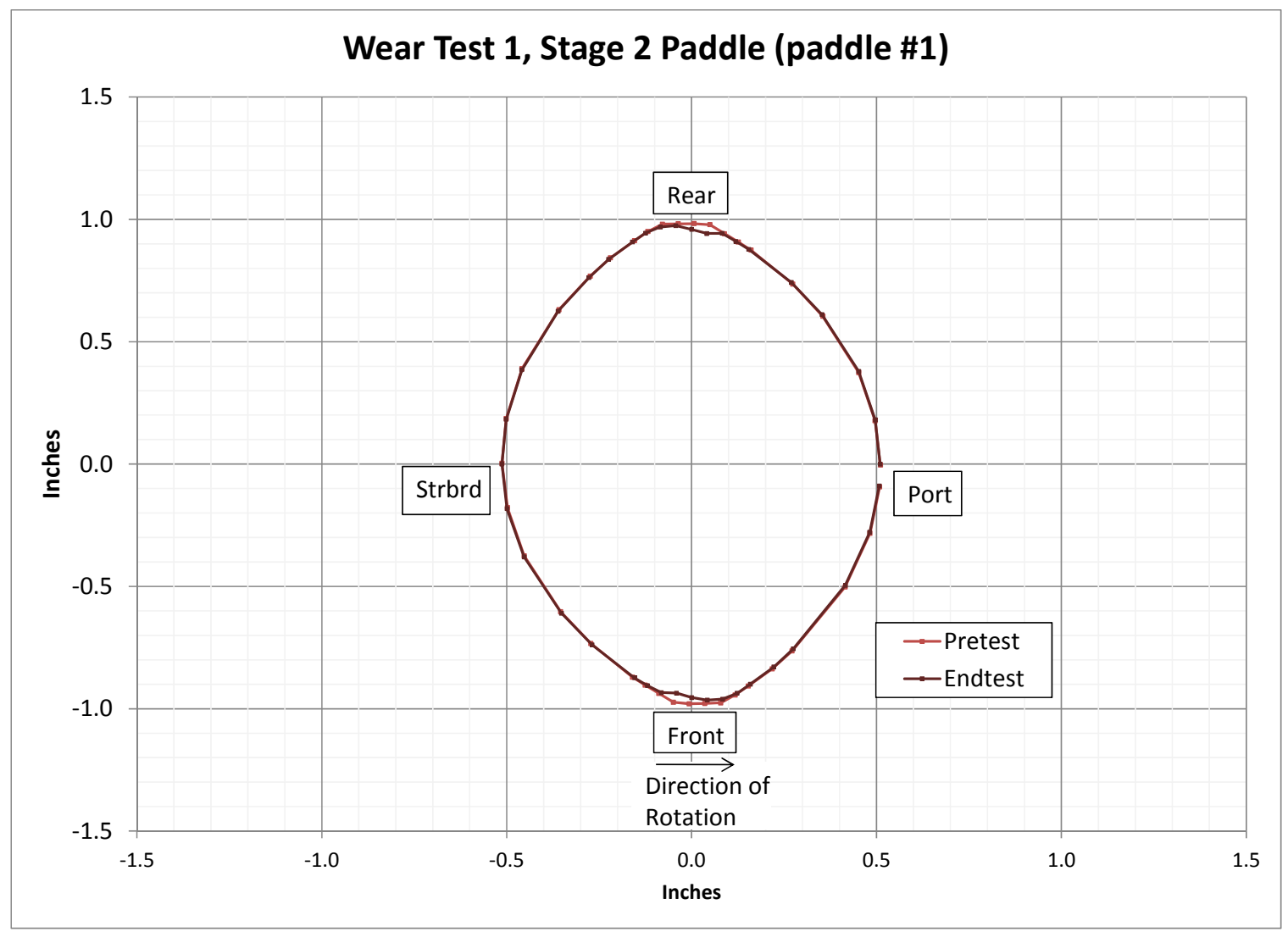

Figure 3-2. Pre- and post-test contour plot for wear test 1, stage 2 flat paddle on the right shaft. 


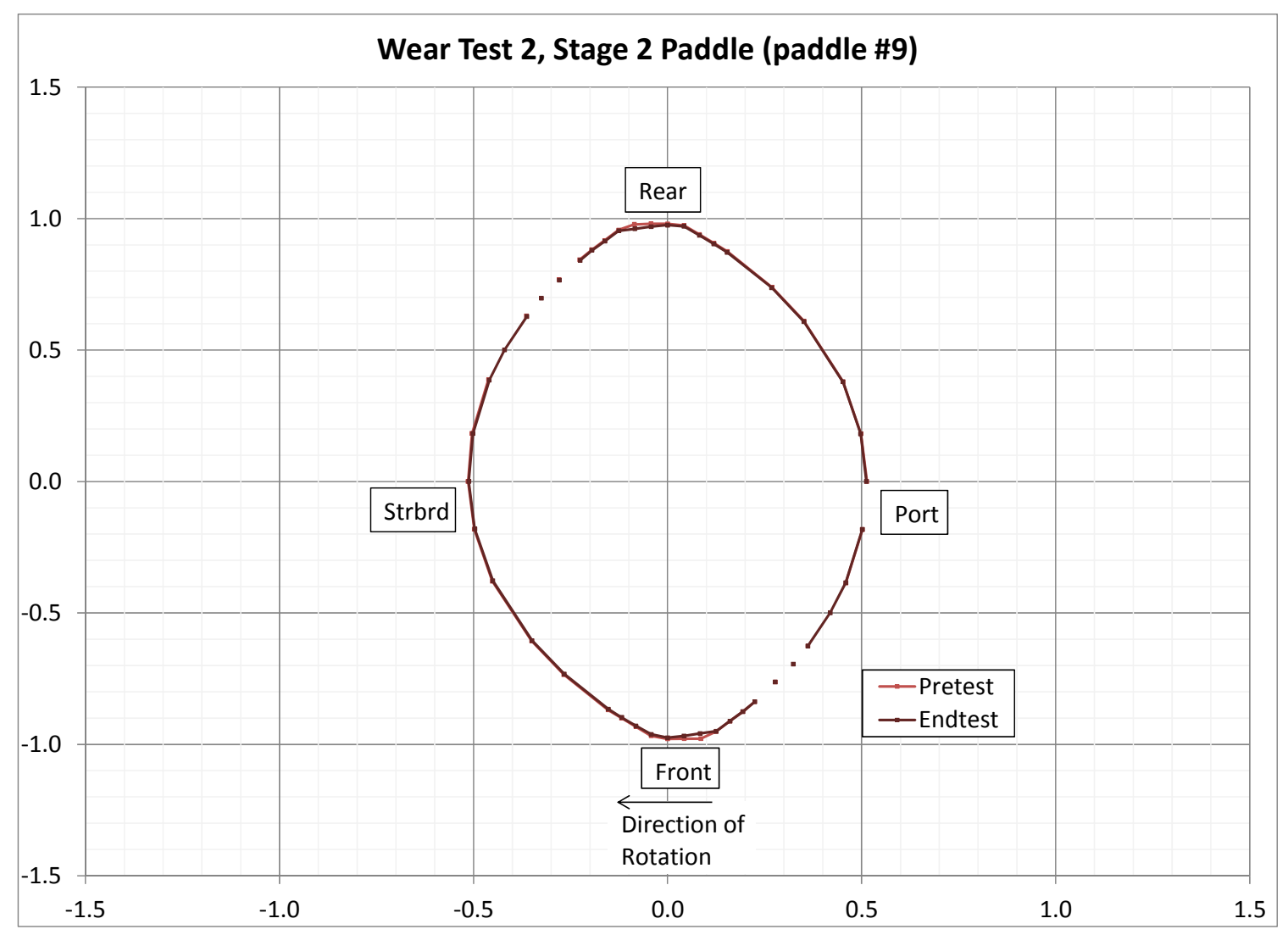

Figure 3-3. Pre- and post-test contour plot for wear test 2, stage 2 helical paddle on right shaft.

Results from the contour plots are compiled in Table 3-1. The reductions in radial height at the paddle tips for the stage 2 and 3 paddles from wear test 1 and 2 are presented. The low, middle and high contour data are presented. Pictures of the corresponding paddle tips are shown below each data set.

A -0.005 inch "filter" was applied to the data to remove values greater than -0.005 inches (corresponding to the uncertainty of the measurement). The filter was applied to better illustrate the location of the greatest wear, an effect that tended to agree with the accompanying photo. Direction of paddle rotation is noted at the side of the data sets. Contour data from the sides of the paddles are not presented in this table because of the lack of significant wear and the increased uncertainty of the measurement (see section 2.4).

The following are observations from the contour measurements:

- The wear depth is approximately twice as great in wear test 1 stage 2 paddles.

- Wear occurs mostly in the middle of the flat paddles.

- Wear occurs mostly at the top of the helical paddles (end leading in the direction of rotation).

- Wear occurs mostly at the trailing edge of the tip on both paddle designs. 
Table 3-1. Wear on the paddle tips for stage 2 and 3 paddles after wear test 1 and 2

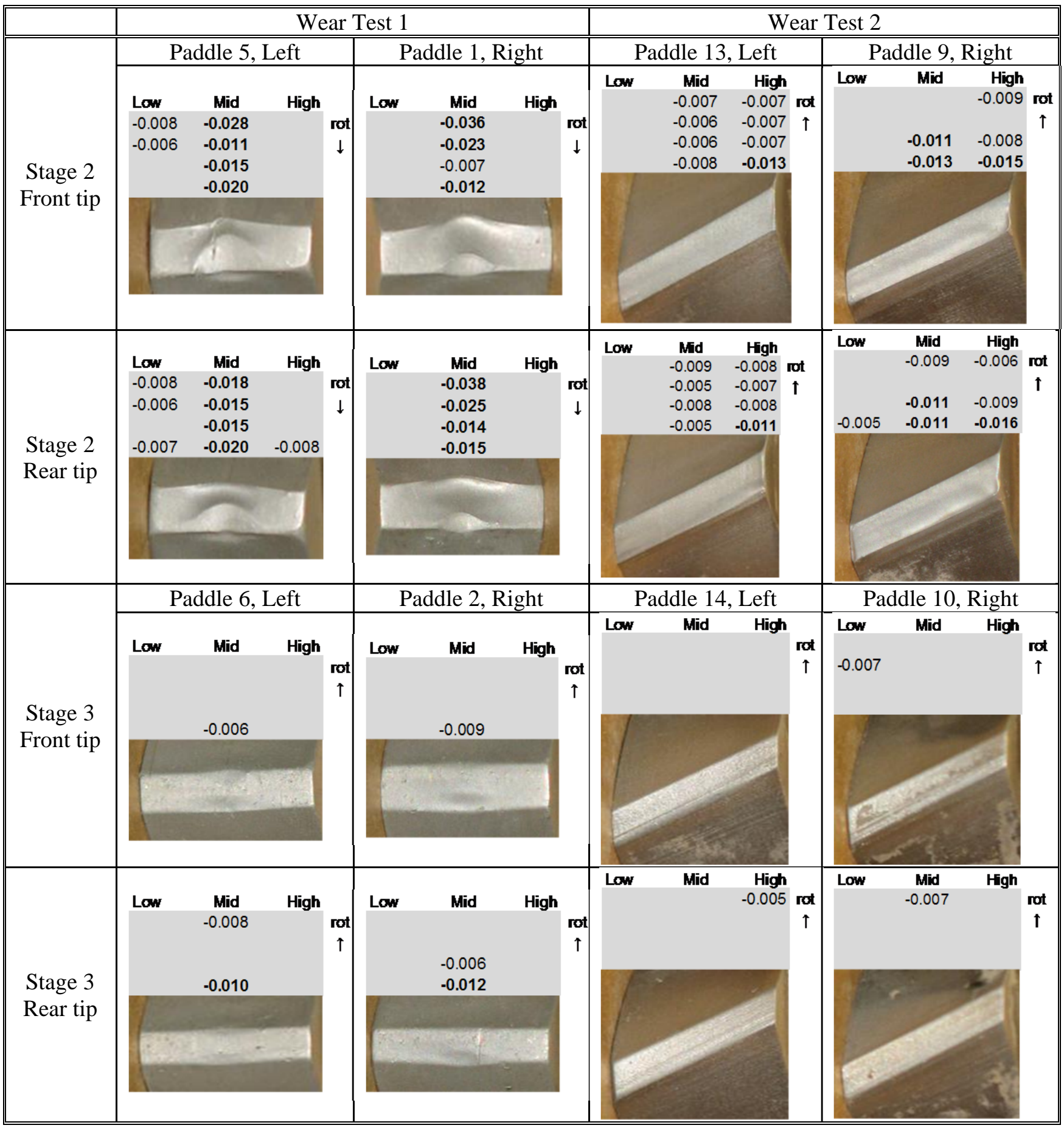




\subsection{Wear on the Mixer Barrel}

The mixer barrel is made of stainless steel and was not expected to show any significant wear within the time frame of this testing. However, wear was evident at the junction of the two barrels mostly at stage 2, with some wear at stage 3 . The wear was evident on the upper housing clamshell and the lower housing clamshell. Figure 3-4 shows the wear at the junction on the upper clamshell.

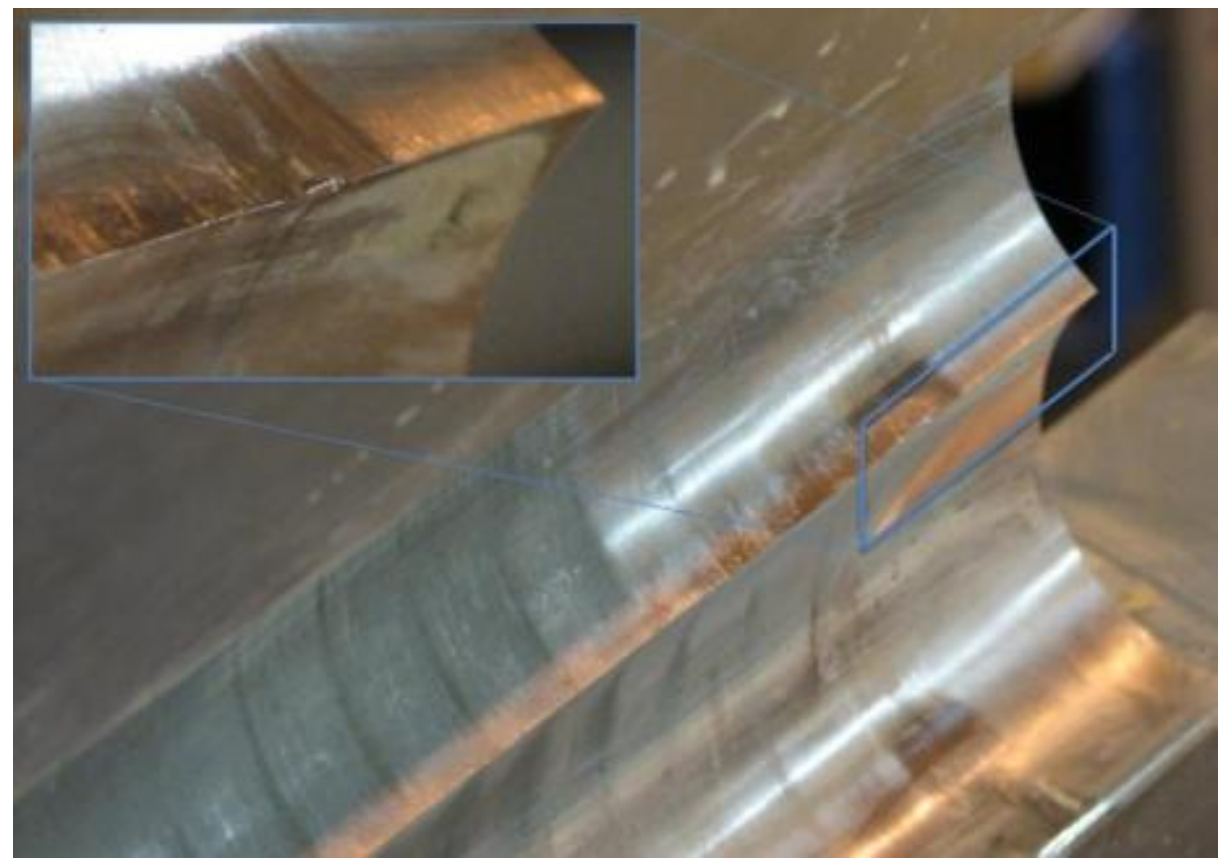

Figure 3-4. Wear at the junction of the inner barrel diameters

The majority of wear occurred on one side of the ridge. Figure 3-5 illustrates the side where the wear occurred. The depth of wear was measured by laying a straight-edge along the junction and inserting the edge of a feeler gage between the housing and the straight-edge. The largest gap was at stage 2 and measured 0.009 inches. 


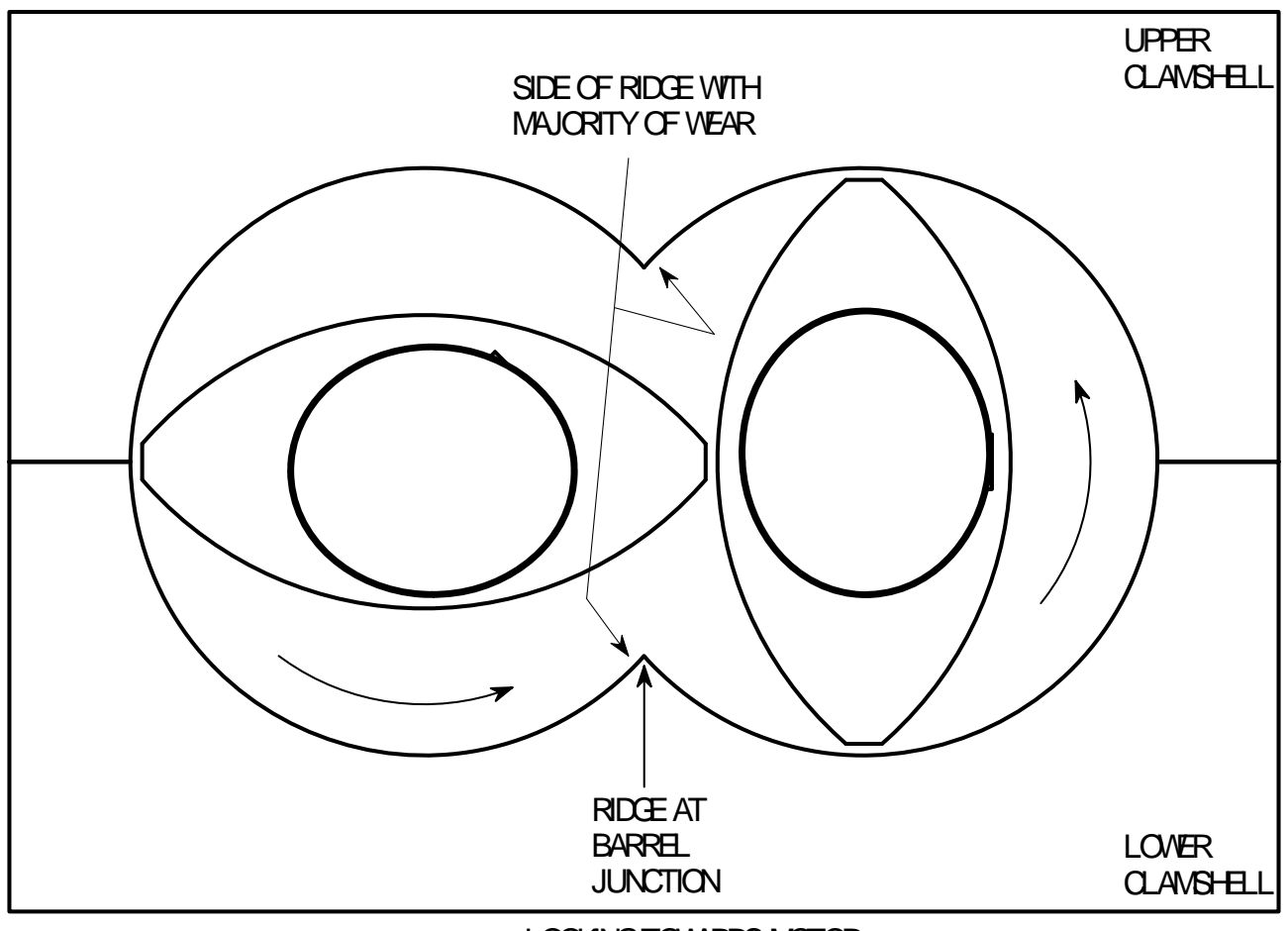

LOOKINGTOMARDS MOTOR

Figure 3-5. Diagram of paddle rotation relative to the measured wear on the inside of the mixer barrel

\subsection{Macrographs of Wear Surfaces}

As shown in Table 3-1, the areas of wear on the flat and helical paddles are different. For the second stage paddles, the majority of the wear occurs at the middle of the flat paddles (Figure 3-6), while the helical paddles wear more at the edges (Figure 3-7). In addition to wear at the tips, the wear is on the leading face of the paddles in the direction of rotation as evidenced by surface polishing; however, the machining marks are still visible on the trailing edge for all the helical paddles. The polishing effect is pronounced on the stage 2 and 3 paddles but not on the stage 4 and 5 paddles (Appendix B). As shown in Figure 3-6 and Figure 3-7, there is some polishing on both sides of the leading and trailing faces of the flat paddles, but only on the leading face of the helical paddles. 

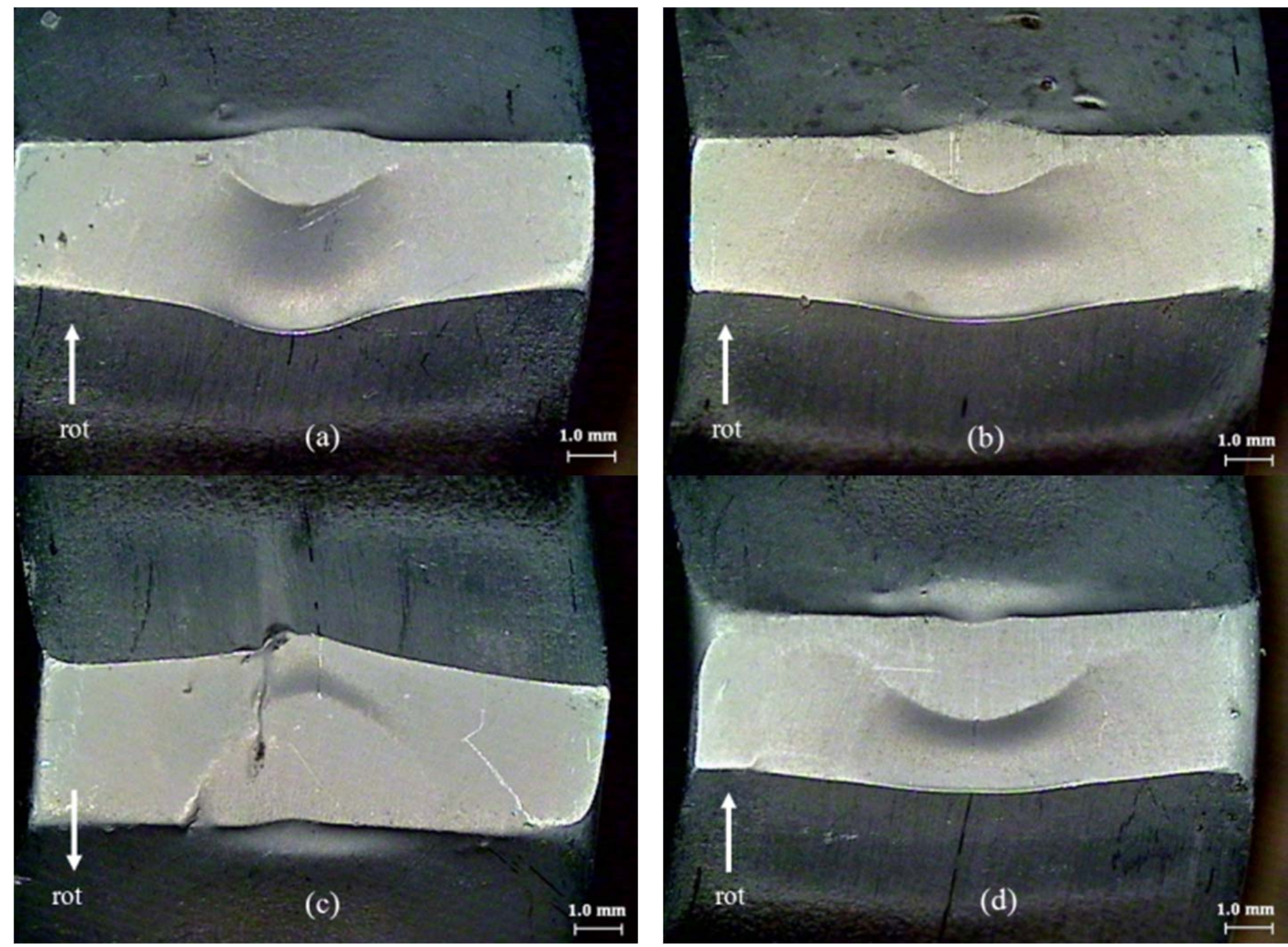

Figure 3-6. Macrographs of second stage flat wear paddles after wear test 1 showing damage to the tip and polishing due to wear on the leading edge for (a) paddle 1, front tip (b) paddle 1, rear tip (c) paddle 5, front tip (d) paddle 5, rear tip 

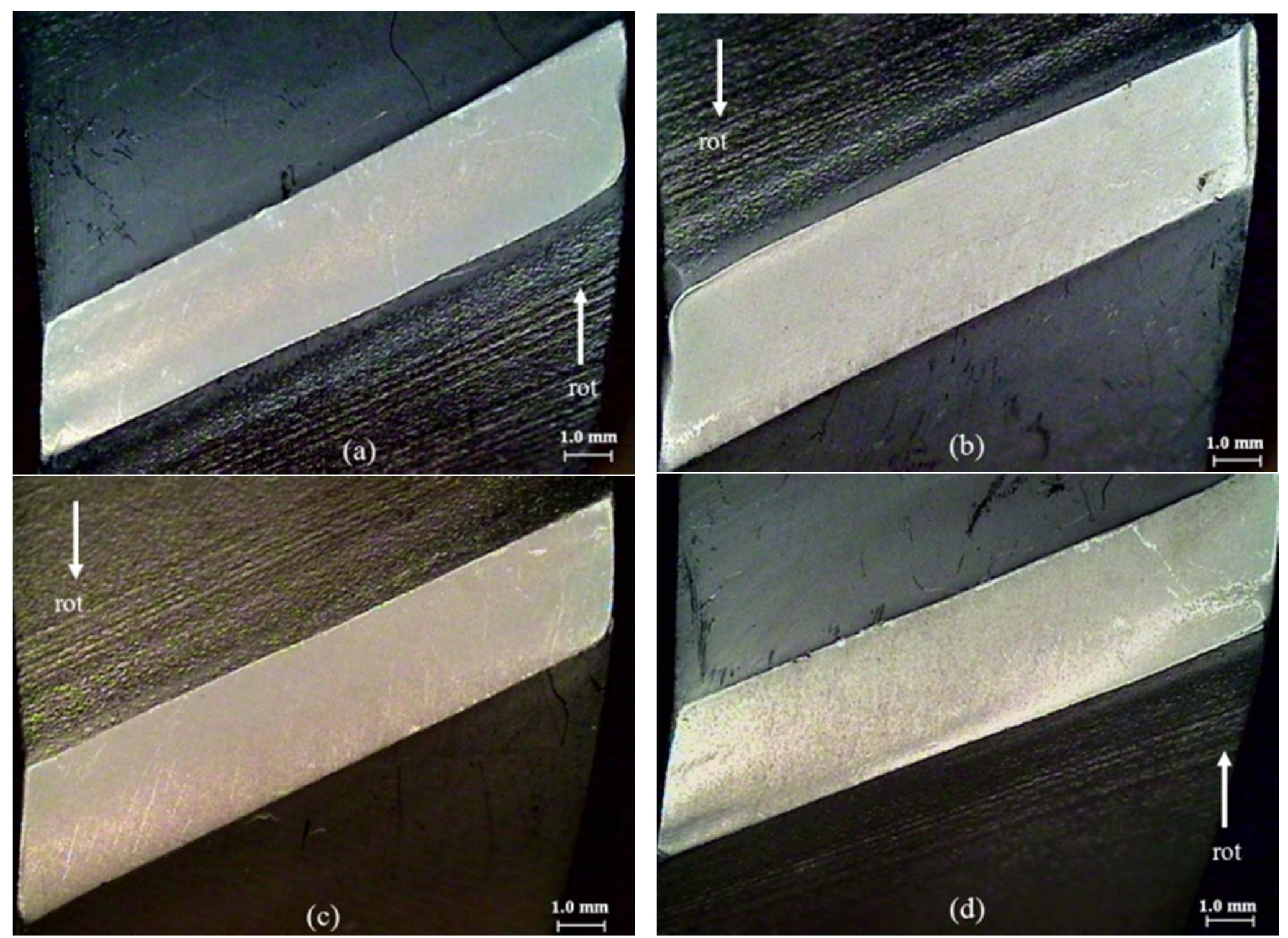

Figure 3-7. Macrographs of second stage helical wear paddles after wear test 2 showing damage to the tip and polishing due to wear on the leading edge for (a) paddle 9, front tip (b) paddle 9, rear tip (c) paddle 13, front tip (d) paddle 13, rear tip 


\subsection{Grout Properties}

Fresh properties of the slurry discharged from the mixer were measured to determine whether the fresh grout properties changed as a result of different paddle configurations. The fresh property measurements taken throughout testing of both the flat and helical paddle configurations are provided in Table 3-2 and Table 3-3, respectively. The fresh property measurements from the first 30 minutes of wear test 2 (helical 1 and 1B) were not included in the average since it was determined that the dry feeder was not at the targeted feed rate. After the 30 minute run was completed, the dry feeder rate was calibrated to deliver dry feeds at a rate of $833 \mathrm{lbs} / \mathrm{hour}$. During this time it was estimated that the dry feed rate was approximately $700 \mathrm{lbs} /$ hour and the lower feed rate did not adversely affect the wear on the helical paddles.

Table 3-2. Fresh grout property results for the flat paddle wear test

\begin{tabular}{|l|c|c|c|}
\hline \multicolumn{1}{|c|}{ Sample } & Plastic Viscosity (cP) & Yield Stress (Pa) & Flow (cm) \\
\hline \hline Flat 1 & 65.78 & 11.68 & 21.91 \\
\hline Flat 2 & 63.96 & 11.67 & 20.96 \\
\hline Flat 3 & 43.22 & 8.43 & 23.18 \\
\hline Flat 4 & 29.04 & 5.40 & 26.67 \\
\hline Flat 5 & 32.44 & 6.40 & 23.50 \\
\hline Flat 6 & 34.62 & 6.59 & 22.23 \\
\hline Flat 7 & 50.17 & 8.98 & 20.32 \\
\hline Average & 45.60 & 8.45 & 22.68 \\
\hline Std. Dev. & 14.94 & 2.52 & 2.09 \\
\hline
\end{tabular}

Table 3-3. Fresh property results for the helical paddle wear test

\begin{tabular}{|l|c|c|c||}
\hline Sample \# & Plastic Viscosity (cP) & Yield Stress (Pa) & Flow (cm) \\
\hline \hline Helical 1 & 21.79 & 3.50 & 31.115 \\
\hline Helical 1B & $\mathrm{nm}$ & $\mathrm{nm}$ & 26.035 \\
\hline Helical 2 & 61.83 & 13.27 & 21.59 \\
\hline Helical 3 & 55.21 & 11.92 & 22.86 \\
\hline Helical 4 & 70.01 & 13.85 & 17.78 \\
\hline Helical 4B & $\mathrm{nm}$ & $\mathrm{nm}$ & 22.225 \\
\hline Helical 5 & 58.34 & 12.12 & 21.59 \\
\hline Helical 5B & 47.33 & 9.48 & 22.86 \\
\hline Helical 6 & 89.78 & 17.46 & 19.05 \\
\hline Helical 6B & 56.43 & 11.68 & 22.225 \\
\hline Helical 7 & 73.33 & 15.16 & 19.685 \\
\hline Helical 7B & 43.63 & 9.44 & 24.13 \\
\hline Helical 8 & 58.59 & 12.31 & $\mathrm{~nm}$ \\
\hline Helical 8B & 45.12 & 9.47 & $\mathrm{~nm}$ \\
\hline Average & 59.96 & 12.38 & 21.40 \\
\hline Std. Dev & 13.63 & 2.51 & 1.96 \\
\hline
\end{tabular}

nm - not measured 
As shown in Table 3-2 and Table 3-3, the fresh properties are slightly higher in the helical paddle wear test than the flat paddle wear test. However, both tests produced grout-like material that is within the processing rage of the SPF; it should be noted that cement is not included in the premix and water was used rather than salt solution, which does affect the rheology of the fresh grout. The SPF, specifically the hopper and pumping systems, have been designed for processing saltstone with a Bingham Plastic yield stress of $21.5 \mathrm{~Pa}^{19}$ The higher rheological properties from the helical wear test are most likely due to the reduced number of shearing paddles in the mixer. However, the flow test data is comparable for both wear tests, indicting the flowability of the grout is unaffected by the paddle configuration.

The variation in the rheological data for each wear test is most likely due to the way the dry feeds enter the mixer from the dry feeder. As noted in section 2.1, the premix is discharged from the hopper in an unsteady fashion, where irregular sized clumps were observed leaving the discharge of the auger, though the auger speed is constant. The reason for this is that the slag and fly ash are not considered free flowing materials due to their particle size. The micron size particles have cohesive (or electro-static) forces that result in clumping flow and by how the discharge of the dry hopper is designed. Once the clump falls into the READCO mixer, it is quickly dispersed and transported by the auger into the mixing chamber; however, some variation in the delivery of premix to the mixer augers would account for the differences in rheology throughout the duration of each wear test. 


\subsection{Conclusions}

The Saltstone Production Facility has a 10-inch Readco-Kurimoto continuous mixer installed that mixes the premix dry feeds and low-level waste salt solution to make fresh (uncured) saltstone slurry. Inspection of the mixer recently removed from service showed significant wear on the first and second paddles after the conveying augers and at the interface of the auger and first set of paddles. A 2-inch Readco-Kurimoto continuous mixer was used to test alternate paddle configurations for use in the 10-inch mixer to decrease the wear rate on the paddles and at the interface.

For this testing, a soft metal with low wear resistance (6000 series aluminum), was used to minimize run time while maximizing wear rate. Two paddle configurations were tested, with the first four paddles after the augers replaced by the wear paddles. The first configuration was all flat paddles, with the first paddle not aligned with the augers and is consistent with present SFT mixer. The second configuration had helical paddles for the first three stages after the augers and a flat paddle at the fourth stage. The first helical paddle was aligned with the auger flight for the second configuration.

The all flat paddle configuration wear rate was approximately double the wear rate of the helical paddles for the first two paddles after the augers. For both configurations, there was little or no wear on the third and fourth paddles based on mass change, indicating that the fully wetted premix materials are much less abrasive than the un-wetted or partially wetted premix. Additionally, inspection of the wear surface of the paddles at higher magnification showed the flat paddles were worn much more than the helical and is consistent with the wear rates. The aligning of the auger discharge flight with the first set of paddles showed to be effective in reducing the wear rate when comparing the helical paddle to the flat paddle.

Changing the paddle configuration from flat to helical resulted in a slight increase in rheological properties. However, both tests produced grout-like material that is within the processing rage of the SPF. The higher rheological properties from the helical wear test are most likely due to the reduced number of shearing paddles in the mixer. However, the flow test data is comparable for both wear tests, indicting the flowability of the grout is unaffected by the paddle configuration.

\subsection{Recommendations and Future Work}

Based on the conclusions of this report and the report that investigated alternate materials of construction for the mixer paddles ${ }^{2}$, the lifetime of the mixer in the SPF can be extended if the different paddle types are strategically placed and highly wear resistant materials are used for the paddles. Since the new mixer is already installed, these changes should be implemented in the spare mixer. The estimate of increased wear resistance can be done with further wear testing as recommended in this section.

Based on the results of this testing, it is recommended for the currently installed ELAWD mixer that paddles at stages 2 through 7 be helical rather than flat, with the first paddles aligned with the augers. Since the liquid inlet was moved, paddles at stages 2 through 5 are only mixing the premix until they reach paddles 5 and 6 where the premix is wetted by the salt solution. This new mixer configuration can be tested in the 2-inch mixer using the same testing methods described in this report. In addition, it is recommended that saltstone engineering monitor the wear of the paddles in the newly installed mixer as part of routine maintenance in order to establish a wear rate of the paddles in service. 
The current testing with the wear paddles should continue as an independent task or as part of other testing with the scaled Saltstone Facility in order to determine a life expectancy of the mixer with the current and recommended paddle configurations.

Other recommendations for future work include reducing the mixer speed to further reduce erosion. The rotational speed of the mixer may be contributing to the wear on the paddles and decreasing the speed of the mixer could reduce wear and increase residence time of the material in the mixer, resulting in more mixing. Since the 2 inch mixer has a variable speed drive, the recommended paddle configuration will be tested at decreasing mixer speeds to determine the impacts of rotational speed on paddle wear and grout mixing. Discussion with the vendor revealed that reducing mixer speed has been beneficial to other customers of theirs. 


\subsection{References}

1. Shah, S., "Evaluate/Recommend Saltstone Mixer Auger/Paddles Material of Construction for Improved Wear Resistance," Savannah River Remediation, HLW-SSF-TTR-20120001, October 27, 2011.

2. Mickalonis, J.I. and Torres, R.D., "Evaluation and Recommendation of Saltstone Mixer Auger/Paddles Materials of Construction for Improved Wear Resistance," Savannah River National Laboratory, SRNL-STI-2012-00379, Revision 0, July 2012.

3. Torres, R.D., Mickalonis, J.I., and Serrato, M.G., "Task Technical and Quality Assurance Plan for Evaluation and Recommendation of Saltstone Mixer Auger/Paddles Materials of Construction for Improved Wear Resistance " Savannah River National Laboratory, SRNL-RP-2011-01646, January 2012.

4. Lookabill, T. and Hopkins, R., "Results of Saltstone Scaled Mixer Test - June 19, 2003," WSP-SSF-2003-0003, July 30, 2003.

5. Carter, A.R., Leita, J.N., Tihey, J.R., and Occhipinti, J.E., "Engineering Position for Saltstone Mixer Testing at Vendor Facility," Savannah River Remediation, SRR-WSE2011-00083, March 30, 2011.

6. Leita, J.N. and Tihey, J.R., "Saltstone Mixer Inspection Summary May 2011".

7. Kalyon, D.M., Polymer Rheology and Processing, Chapter 28: Mixing in Continuous Processors.

8. "Readco Kurimoto, LLC, Continuous Processors", 2010.

9. Lawal, A. and Kalyon, D.M., "Mechanisms of Mixing in Single and Co-Rotating Twin Screw Extruders," Polym. Eng. Sci., 35, [17] 1325 - 38 (1995).

10. Meijer, H.E.H. and Elemans, P.H.M., "The Modeling of Continuous Mixers, Part I: The Corotating Twin-screw Extruder," Polym. Eng. Sci., 28, [5] 275 - 90 (1988).

11. Myers, S.R.K., Inc), to M. M. Reigel, E. K. Hansen, and A. B. Barnes, Personal Communication

12. Serrato, M.G., Fowley, M.D., and Reigel, M.M., "Initial Batch Run of the 2 inch Continuous Scaled Mixer," Savannah River National Laboratory, SRNL-L3100-201200042, March 29, 2012.

13. Staub, A.V., "Technical Assistance Request: Scaled Saltstone Process Development," Savannah River Remediation, HLW-SSF-TAR-2011-0002, Revision 0, January 2011.

14. Desale, G.R., Gandhi, B.K., and Jain, S.C., "Slurry Erosion of Ductile Materials Under Normal Impact Condition," Wear, 264, 322-30 (2008).

15. Desale, G.R., Gandhi, B.K., and Jain, S.C., "Development of Correlations for Predicting the Slurry Erosion of Ductile Materials," Journal of Tribology, 133, [031603] 1-10 (2011). 
16. Langton, C.A. and Burket, P.R. and Hansen, E.K. and Herman, D.T., et al., "Tank 50 Batch 0 Saltstone Formulation Testing," Savannah River National Laboratory, WSRCTR-2005-00498, January 30, 2006.

17. Hansen, E.K., "Physical Characterization of FY2004 Saltstone Simulant Slurries," Savannah River National Laboratory, WSRC-TR-2005-00365, Revision 0, December 2005.

18. "Standard Test Method for Flow Consistency of Controlled Low Strength Material (CLSM)," ASTM International, ASTM D 6103 - 04.

19. Hansen, E.K., Pickenheim, B.R., Leishear, R.A., Marzolf, A.D., et al., "ELAWD Grout Hopper Mock-Up Testing," Savannah River National Laboratory, SRNL-STI-201100465, Revision 0, October 2011. 
SRNL-STI-2012-00549

Revision 0

Appendix A. Saltstone 10-inch Mixer Paddle Assemblies 


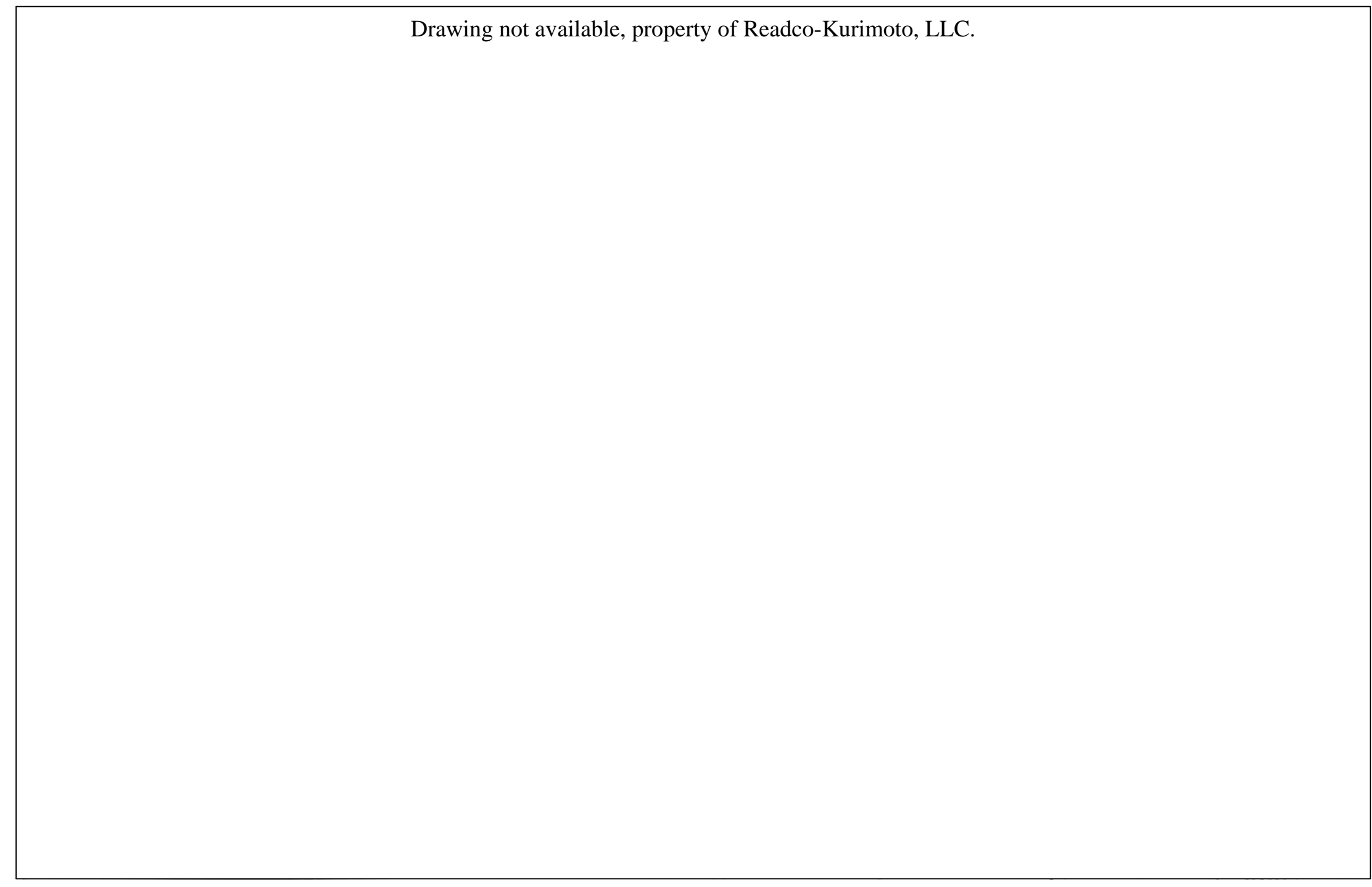

Figure A-1. Paddle assembly for the 10-inch mixer in service in the SPF from 2003 to 2011 
Drawing not available, property of Readco-Kurimoto, LLC.

Figure A-2. Paddle assembly for the 10-inch mixer installed in the SPF in 2012 
SRNL-STI-2012-00549

Revision 0

Appendix B. Macrographs of Paddle Wear 

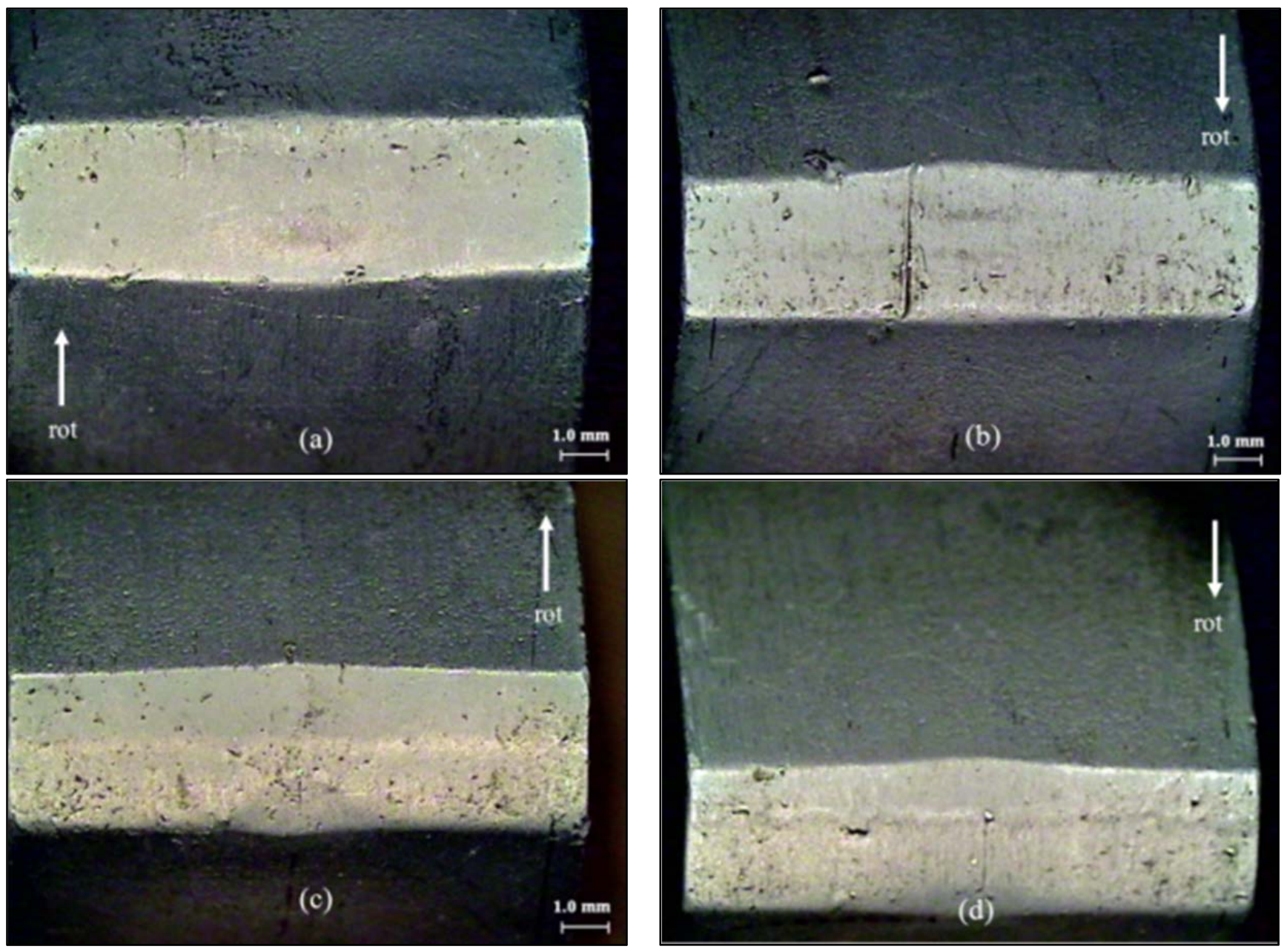

Macrographs of third stage flat wear paddles showing damage to the tip on (a) paddle 2, front tip (b) paddle 2, rear tip (c) paddle 6, front tip (d) paddle 6, rear tip. 

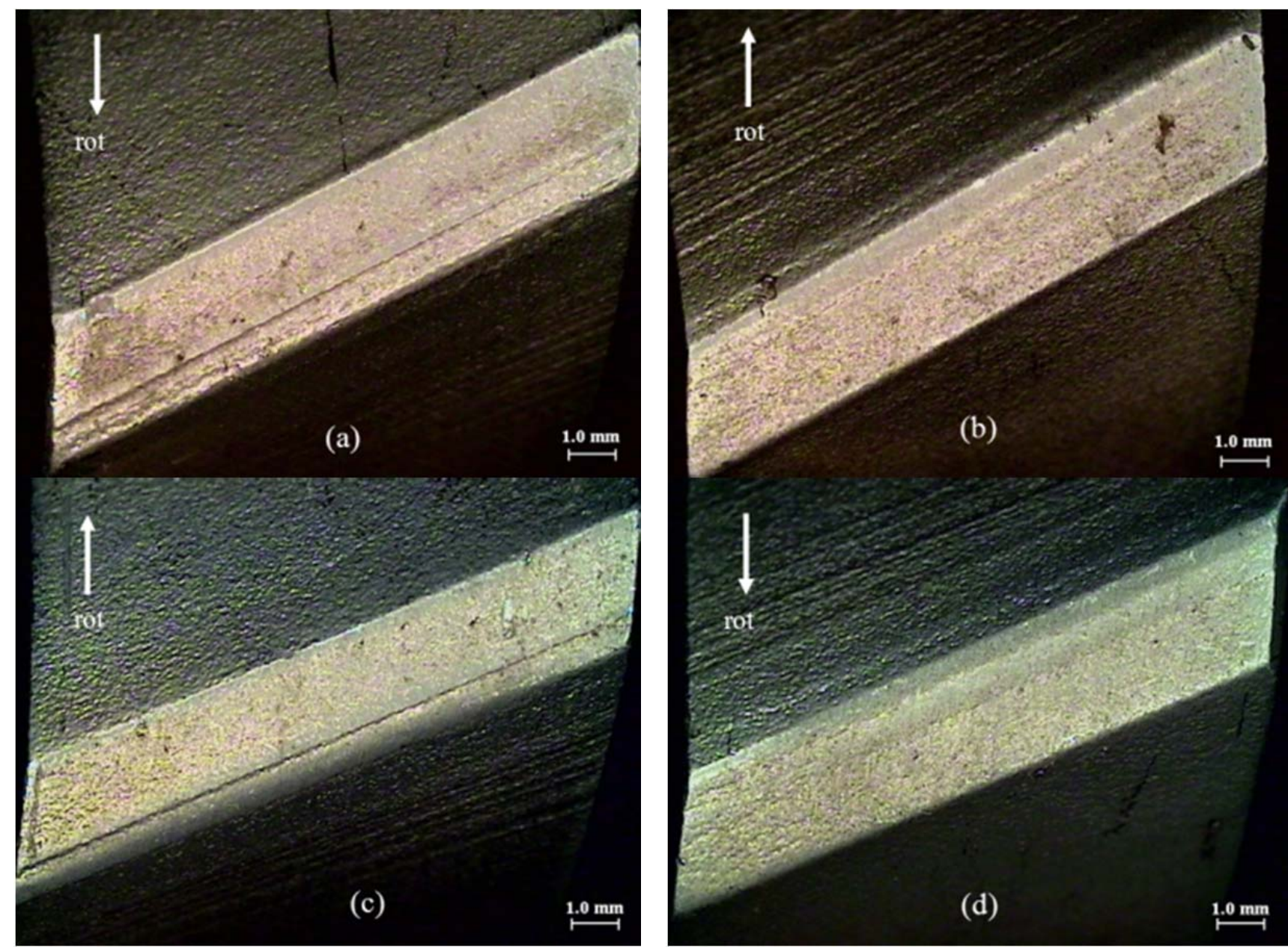

Macrographs of third stage helical wear paddles showing slight damage to the tip at the edges and minimal polishing due to wear on the leading edge for (a) paddle 10, front tip (b) paddle 10, rear tip (c) paddle 14, front tip (d) paddle 14, rear tip. Note the horizontal machining marks still visible on all the paddles, specifically on the trailing face. 

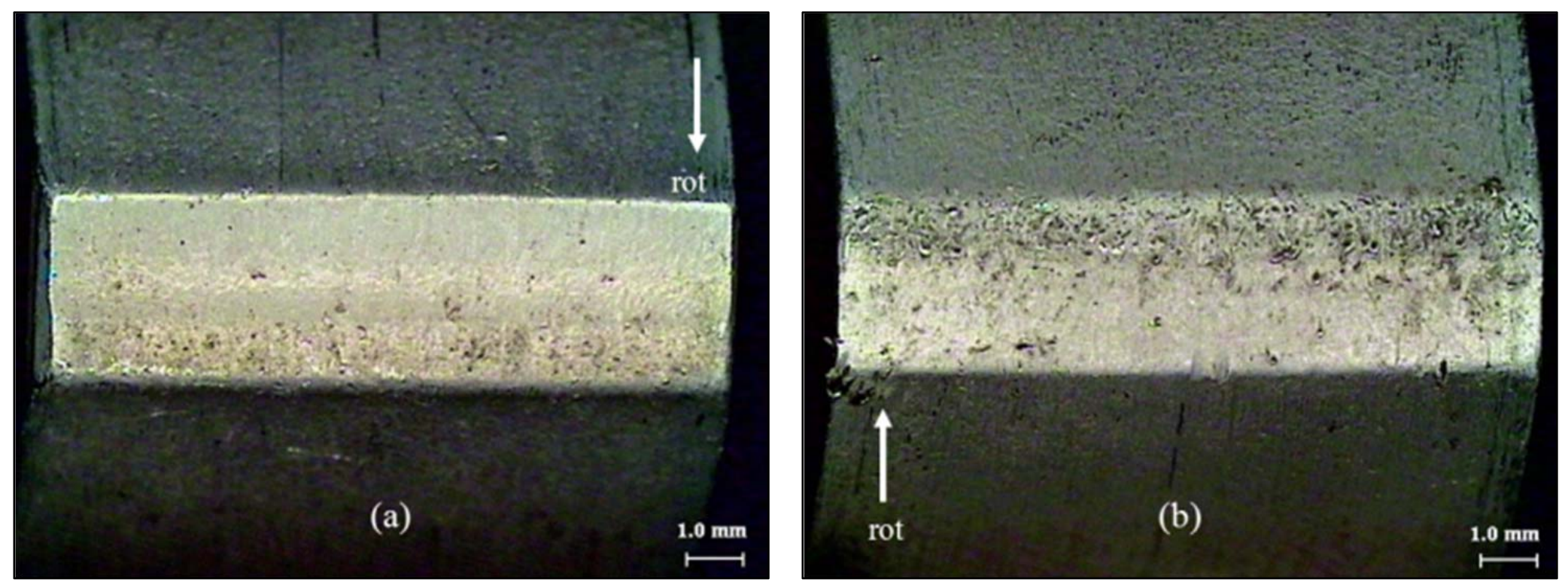

Macrographs of fourth stage flat wear paddles showing slight damage to the tip at the edges and minimal polishing due to wear on the leading edge for (a) paddle 7, front tip (b) paddle 7, rear tip. Macrographs of paddle 3 are not available. Note that wear is more localized to leading edge of the paddle tip, rather than wear occurring on the entire paddle tip. 


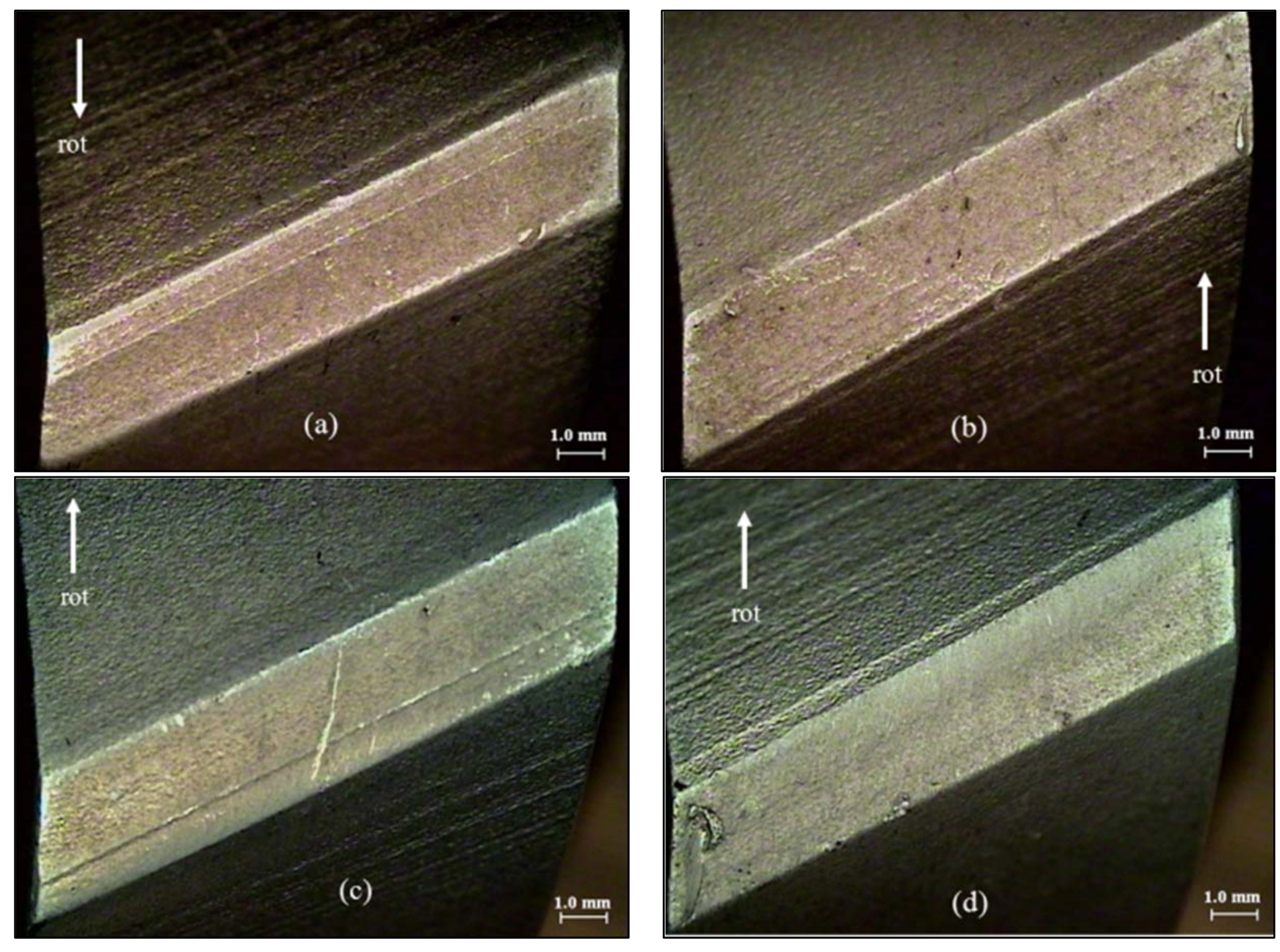

Macrographs of third stage helical wear paddles showing slight damage to the tip at the edges and minimal polishing due to wear on the leading edge for (a) paddle 11, front tip (b) paddle 11, rear tip (c) paddle 15, front tip (d) paddle 15, rear tip. Note the horizontal machining marks still visible on all the paddles, specifically on the trailing face, also the ridge in the middle of the paddle tip is an artifact of machining. 

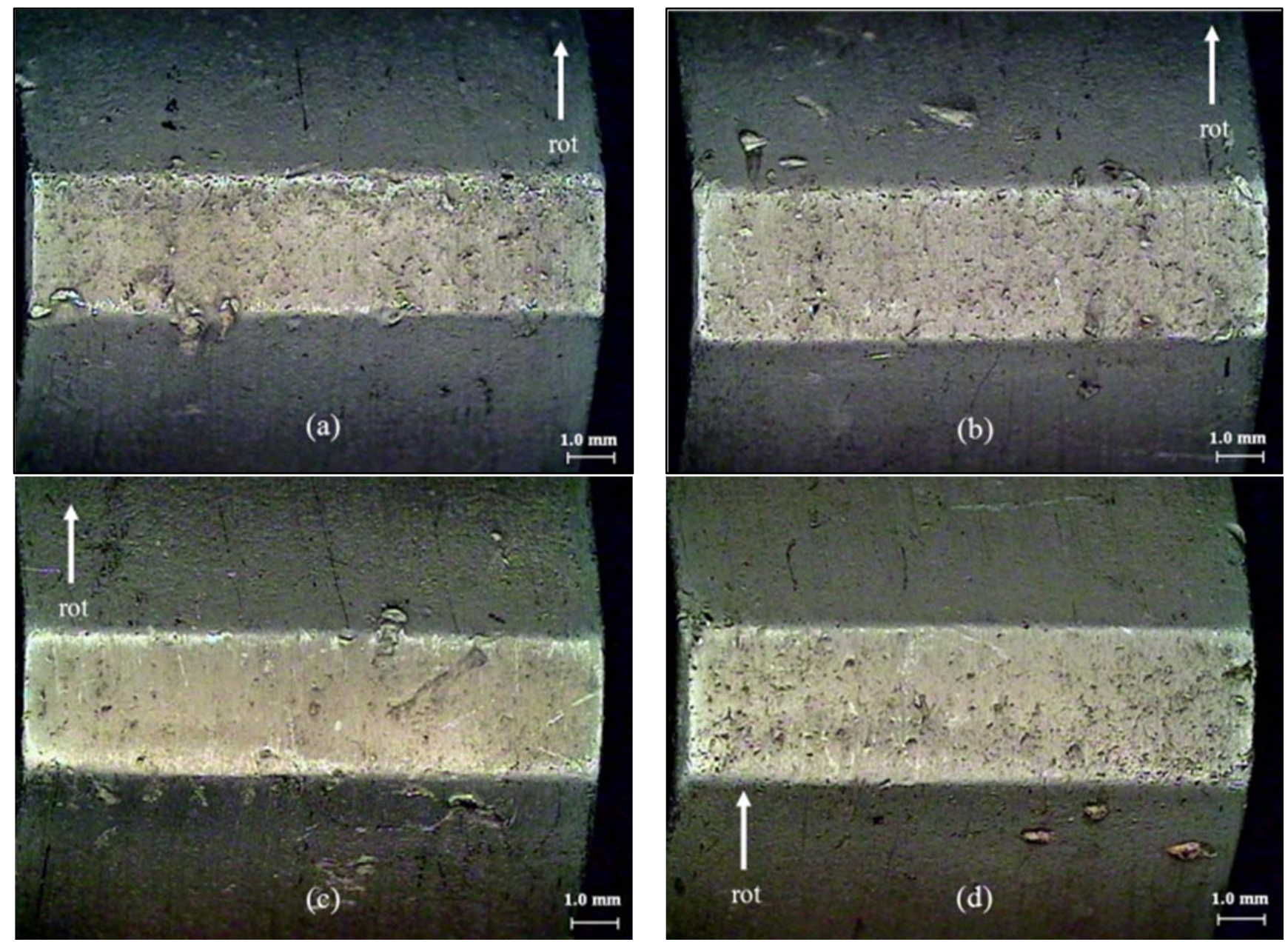

Macrographs of fourth stage flat wear paddles after two wear tests (a) paddle 4, front tip (b) paddle 4, rear tip (c) paddle 8, front tip (d) paddle 8, rear tip. 


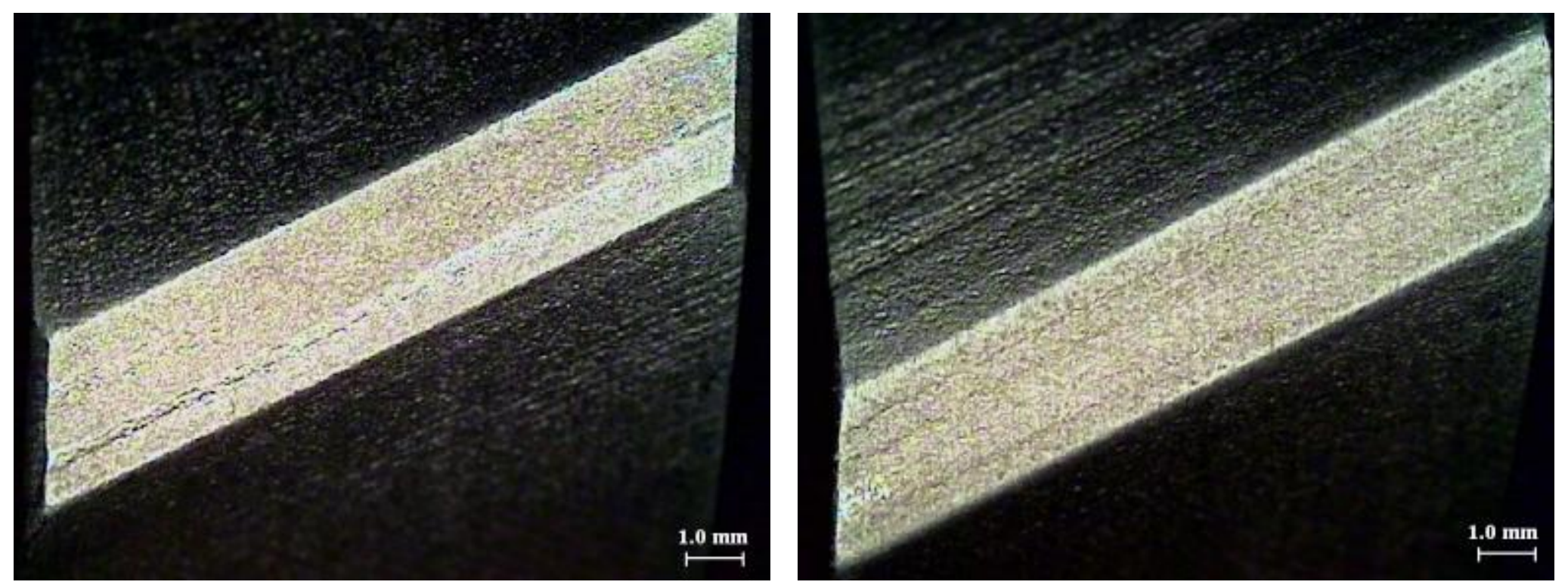

Macrographs of the (a) front tip (b) rear tip of an aluminum helical paddle that was not run in the mixer. 


\section{Distribution:}

\begin{tabular}{|l|l|}
\hline S. L. Marra & $773-\mathrm{A}$ \\
\hline S. D. Fink & $773-\mathrm{A}$ \\
\hline K. M. Fox & $999-\mathrm{W}$ \\
\hline B. J. Giddings & $786-5 \mathrm{~A}$ \\
\hline C. C. Herman & $999-\mathrm{W}$ \\
\hline F. M. Pennebaker & $773-42 \mathrm{~A}$ \\
\hline P. M. Almond & $773-43 \mathrm{~A}$ \\
\hline A. D. Cozzi & $999-\mathrm{W}$ \\
\hline R. E. Eibling & $999-\mathrm{W}$ \\
\hline E. K. Hansen & $999-\mathrm{W}$ \\
\hline C. A. Langton & $773-43 \mathrm{~A}$ \\
\hline D. H. Miller & $999-\mathrm{W}$ \\
\hline B. R. Pickenheim & $999-\mathrm{W}$ \\
\hline M. M. Reigel & $999-\mathrm{W}$ \\
\hline M. G. Serrato & $773-42 \mathrm{~A}$ \\
\hline D. B. Stefanko & $773-43 \mathrm{~A}$ \\
\hline J. M. Bricker & $704-27 \mathrm{~S}$ \\
\hline K. D. Dixon & $704-14 \mathrm{Z}$ \\
\hline J. N. Leita & $704-\mathrm{Z}$ \\
\hline K. R. Liner & $704-\mathrm{S}$ \\
\hline P. D. Mason & $704-14 \mathrm{Z}$ \\
\hline P. W. Norris & $704-29 \mathrm{~S}$ \\
\hline J.E. Occhipinti & $704-\mathrm{S}$ \\
\hline J. W. Ray & $704-\mathrm{S}$ \\
\hline S. C. Shah & $704-14 \mathrm{Z}$ \\
\hline D. C. Sherburne & $704-\mathrm{S}$ \\
\hline A. V. Staub & $704-27 \mathrm{~S}$ \\
\hline J. R. Tihey & $704-\mathrm{Z}$ \\
\hline P. R. Jackson & $703-46 \mathrm{~A}$ \\
\hline K. H. Subramanian & $249-8 \mathrm{H}$ \\
\hline & \\
\hline & \\
\hline
\end{tabular}

